\title{
Survey of Advanced Generation IV Reactor Parameters for Integrated Energy System Modeling Capabilities
}

\section{March | 2021}

Scott William Nelson

Michael Scott Greenwood

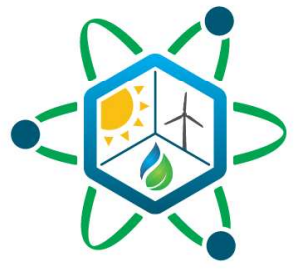




\section{DOCUMENT AVAILABILITY}

Reports produced after January 1, 1996, are generally available free via US Department of Energy (DOE) SciTech Connect.

Website www.osti.gov

Reports produced before January 1, 1996, may be purchased by members of the public from the following source:

National Technical Information Service

5285 Port Royal Road

Springfield, VA 22161

Telephone 703-605-6000 (1-800-553-6847)

TDD 703-487-4639

Fax 703-605-6900

E-mail info@ntis.gov

Website http://classic.ntis.gov/

Reports are available to DOE employees, DOE contractors, Energy Technology Data Exchange representatives, and International Nuclear Information System representatives from the following source:

Office of Scientific and Technical Information

PO Box 62

Oak Ridge, TN 37831

Telephone 865-576-8401

Fax 865-576-5728

E-mail reports@osti.gov

Website http://www.osti.gov/contact.html

This report was prepared as an account of work sponsored by an agency of the United States Government. Neither the United States Government nor any agency thereof, nor any of their employees, makes any warranty, express or implied, or assumes any legal liability or responsibility for the accuracy, completeness, or usefulness of any information, apparatus, product, or process disclosed, or represents that its use would not infringe privately owned rights. Reference herein to any specific commercial product, process, or service by trade name, trademark, manufacturer, or otherwise, does not necessarily constitute or imply its endorsement, recommendation, or favoring by the United States Government or any agency thereof. The views and opinions of authors expressed herein do not necessarily state or reflect those of the United States Government or any agency thereof. 
ORNL/SPR-2021/1947

\section{SURVEY OF ADVANCED GENERATION IV REACTOR PARAMETERS FOR INTEGRATED ENERGY SYSTEM MODELING CAPABILITIES}

Scott W. Nelson

M. Scott Greenwood

March 2021 


\section{CONTENTS}

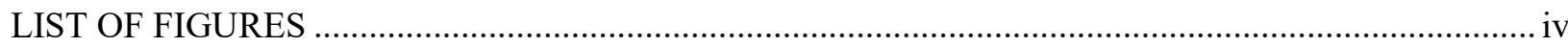

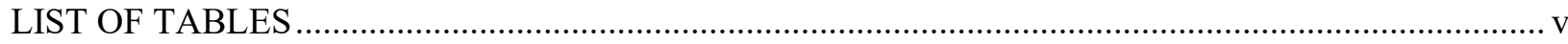

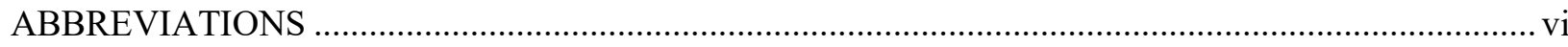

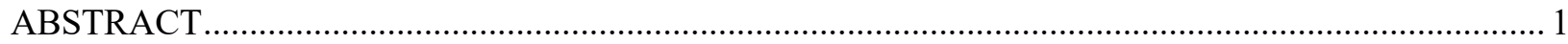

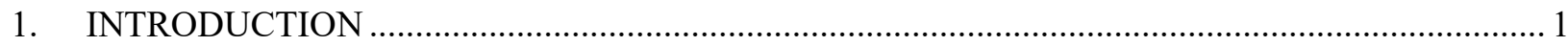

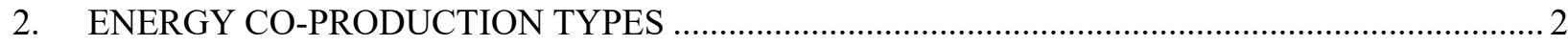

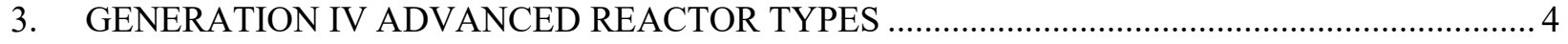

3.1 GAS-COOLED REACTORS ............................................................................. 5

3.1.1 Gas-Cooled Reactors: Primary Description.......................................................... 7

3.1.2 Gas-Cooled Reactors: Secondary Description ......................................................... 7

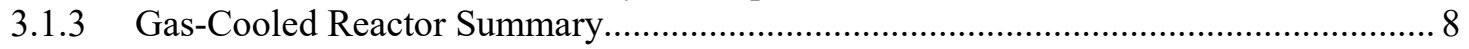

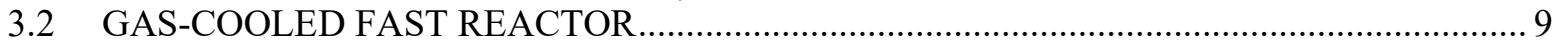

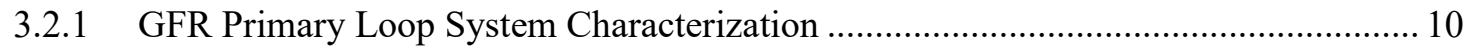

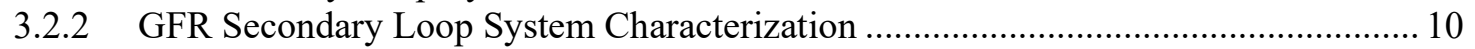

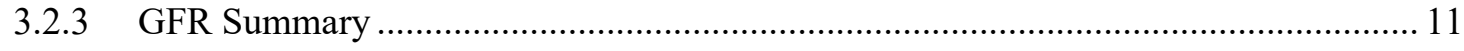

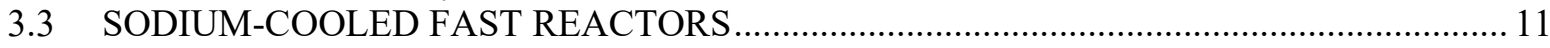

3.3.1 Sodium-Cooled Fast Reactor Primary Loop System Characterization ........................ 13

3.3.2 Sodium-Cooled Secondary Loop System Characterization ......................................... 13

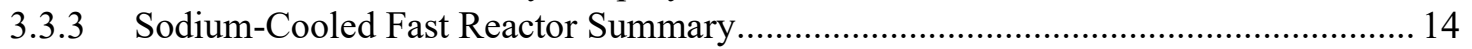

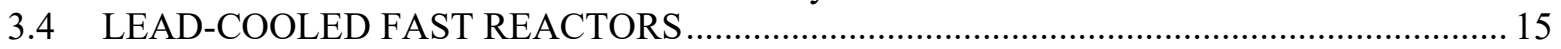

3.4.1 Lead-Cooled Primary Loop System Characterization ............................................. 17

3.4.2 Lead-Cooled Secondary Loop System Characterization ........................................... 17

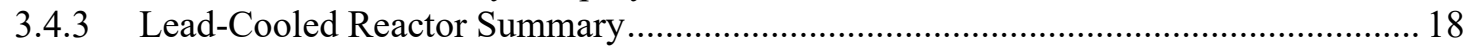

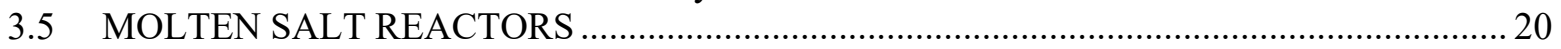

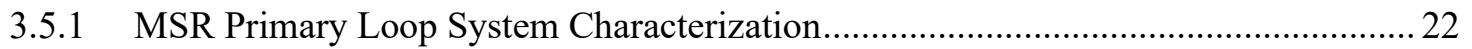

3.5.2 MSR Power Production Loop System Characterization.............................................. 23

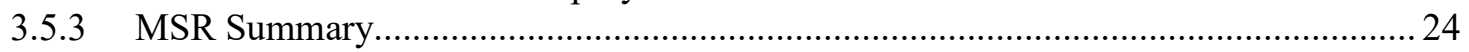

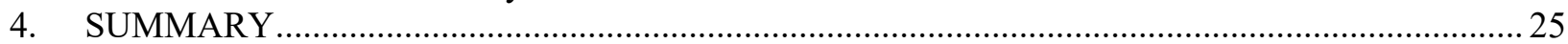

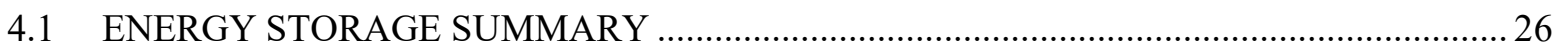

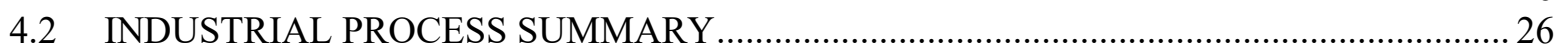

4.3 Dynamic System Models ADVANCED REACTOR INTEGRATED ENERGY

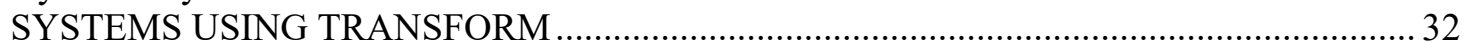

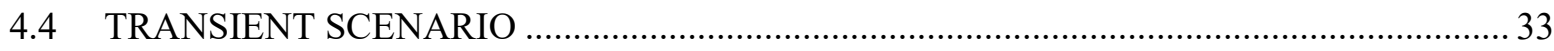

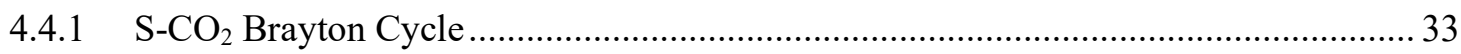

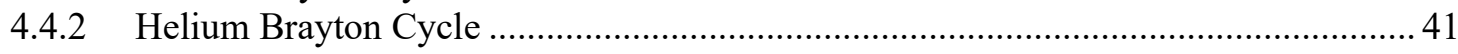

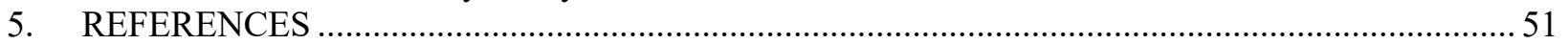




\section{LIST OF FIGURES}

Figure 3.5-1. Breakdown of Reviewed Reactor Types....................................................................... 25

Figure 4.2-1. Industrial process needs vs. average power cycle temperatures $\left({ }^{\circ} \mathrm{C}\right)$ of advanced

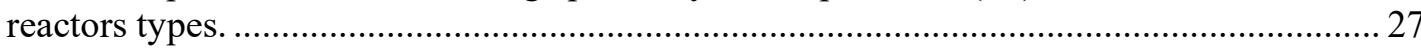

Figure 4.2-2. Industry NAICS plants and GHGRP reporting plants based on industry type..................... 28

Figure 4.4-1. Normalized power history of Cattenom Unit 2 used as the driving electrical

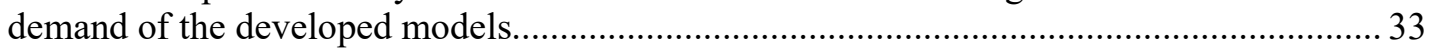

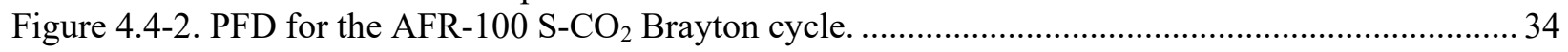

Figure 4.4-3. Example of a unit test of individual components to verify nominal data.............................36

Figure 4.4-4. A steady-state model of the $\mathrm{S}-\mathrm{CO}_{2}$ BOP for the AFR-100 ............................................ 36

Figure 4.4-5. Dynamic model of the $\mathrm{S}-\mathrm{CO}_{2} \mathrm{BOP}$ for the AFR-100 with some basic controls

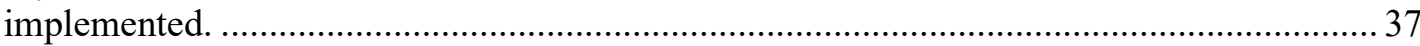

Figure 4.4-6. $\mathrm{S}_{-} \mathrm{CO}_{2}$ model comparison of generated to setpoint power. .............................................. 39

Figure 4.4-7. $\mathrm{S}-\mathrm{CO}_{2}$ model split fractions demonstrating the change in flows to match requested

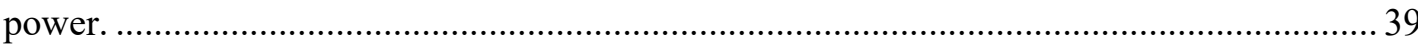

Figure 4.4-8. State points of the S- $\mathrm{CO}_{2}$ of the dynamic model's simulation at the beginning. ................. 40

Figure 4.4-9. State points of the S- $\mathrm{CO}_{2}$ of the dynamic model's simulation during the middle of

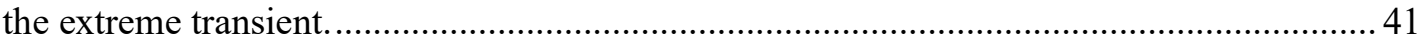

Figure 4.4-10. Basic pebble bed reactor schematic based on the PBMR design [13] ........................... 44

Figure 4.4-11. Basic Stead State Precooler Model steady-state precooler model..................................... 45

Figure 4.4-12. Steady-state pebble bed reactor model .......................................................................... 46

Figure 4.4-13. Power generation comparison between simulation and the Cattenom Unit 2 set

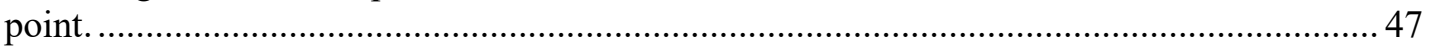

Figure 4.4-14. Temperature vs. specific entropy for transient start. .................................................... 48

Figure 4.4-15. Temperature vs. specific entropy diagram at the lowest power timestep.......................... 49 


\section{LIST OF TABLES}

Table 3.1-1. Industrial process maximum temperature summary [6] f................................................. 4

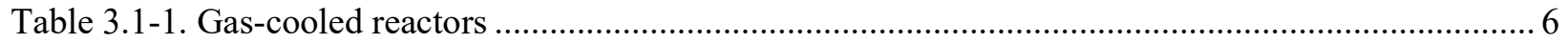

Table 3.1-2. Gas-cooled reactor primary reactor system parameter summary ...................................... 7

Table 3.1-3. Gas-cooled reactor secondary system parameter summary .............................................. 8

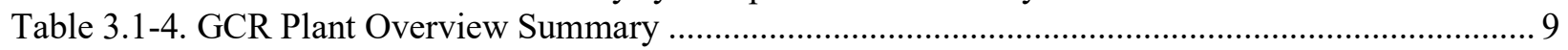

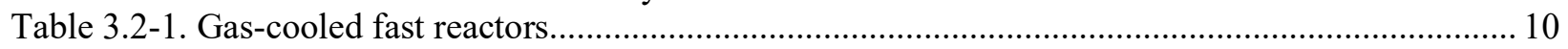

Table 3.2-2. Gas-cooled fast reactor primary system parameter summary ...................................... 10

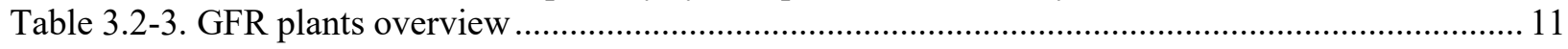

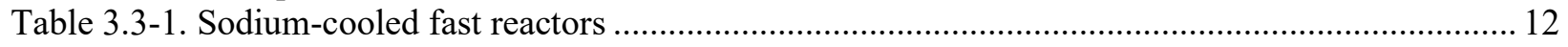

Table 3.3-2. Sodium-cooled fast reactor primary system parameter summary ..................................... 13

Table 3.3-3. Sodium-cooled fast reactor power production system parameter summary .......................... 14

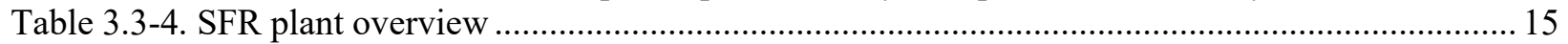

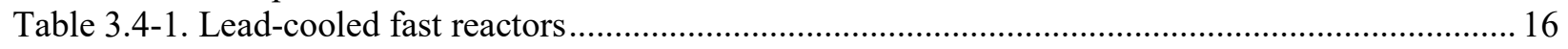

Table 3.4-2, Lead-cooled reactor primary system parameter summary ................................................ 17

Table 3.4-3. Lead-cooled reactor secondary system parameter summary ............................................... 18

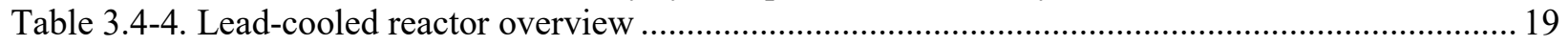

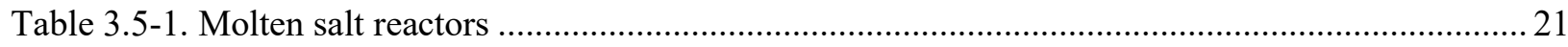

Table 3.5-2. Molten salt reactor primary system parameter summary .................................................... 22

Table 3.5-3. Molten salt reactor secondary system parameter summary ................................................ 23

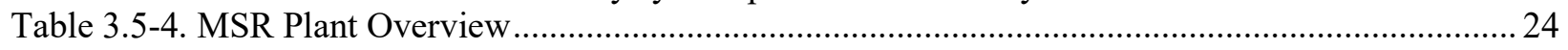

Table 4.2-1. Target industry heat input consumption summary .........................................................29

Table 4.2-2. Summary of surveyed advanced reactors for potential applications in process heat

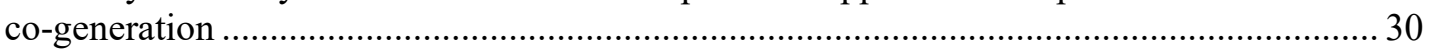

Table 4.2-3. Possible Reactors Based on the Target industry Heat and Temperature Requirements .......... 31

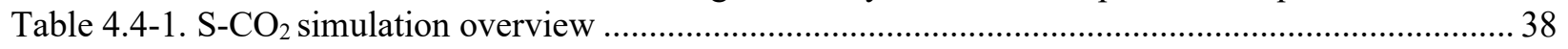

Table 4.4-2. Nominal temperature and pressure conditions for a $400 \mathrm{MWt}$ pebble bed gas-cooled

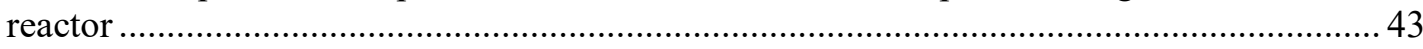

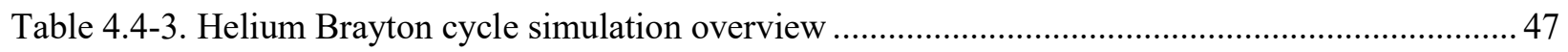




\section{ABBREVIATIONS}

$\begin{array}{ll}\text { BWR } & \text { boiling water reactor } \\ \text { DOE } & \text { US Department of Energy } \\ \text { ES } & \text { energy storage } \\ \text { FBR } & \text { fast breeder reactor } \\ \text { FR } & \text { fast reactor } \\ \text { GCR } & \text { gas-cooled reactor } \\ \text { GFR } & \text { gas-cooled fast reactor } \\ \text { GHG } & \text { green house gas } \\ \text { GHGRP } & \text { Greenhouse Gas Reporting Program } \\ \text { GIF } & \text { Generation IV International Forum } \\ \text { HTGR } & \text { high-temperature gas-cooled reactor } \\ \text { HWR } & \text { heavy water reactor } \\ \text { IES } & \text { integrated energy system } \\ \text { LFR } & \text { lead-cooled fast reactor } \\ \text { MOX } & \text { mixed oxide fuel } \\ \text { MSR } & \text { molten salt reactor } \\ \text { MSRE } & \text { Molten Salt Reactor Experiment } \\ \text { MWe } & \text { megawatt electric } \\ \text { MWt } & \text { megawatt thermal } \\ \text { NAICS } & \text { North American Industry Classification System } \\ \text { PFD } & \text { process flow diagram } \\ \text { PI } & \text { proportional-integral [controller] } \\ \text { PID } & \text { proportional-integral derivative [controller] } \\ \text { S-CO }{ }_{2} \text { or sCO } \text { s }_{2} & \text { supercritical carbon dioxide } \\ \text { SCR } & \text { supercritical water cooled reactor } \\ \text { SCWR } & \text { supercritical-water reactor } \\ \text { SFR } & \text { sodium-cooled fast reactor } \\ \text { SMR } & \text { small modular reactor } \\ \text { TRISO } & \text { tristructural isotropic [particle fuel]] } \\ \text { TRL } & \text { technological readiness level } \\ \text { VHTR } & \text { very high temperature reactor } \\ & \end{array}$




\begin{abstract}
This paper is to categorize and characterize advanced Generation IV nuclear reactors that are not water based according to the key parameters for the Integrated Energy Systems (IES) project [1]. A key goal of the IES project is to assess the economic viability of including an advanced nuclear reactor into an IES. The landscape of advanced reactors is heterogeneous: several unique designs with different heat profiles are currently being studied and designed. This report provides a high-level perspective of advanced reactor concepts, including primary loop nuclear output temperatures and operation schemes that could affect secondary side power production or storage. For example, this report addresses the type of thermodynamic system (i.e., direct helium and an indirect supercritical $\mathrm{CO}_{2}\left[\mathrm{~S}-\mathrm{CO}_{2}\right]$ Brayton cycle) and the various pressures and temperatures on the secondary side that are expected to be provided by the various primary side reactor types. Based on these characteristics, it may be possible to determine which type of nuclear power plant could be the most economical for analysis in the IES framework for power production coupled with energy storage and waste heat utilization.

The results of this effort will serve as input for model development of various secondary side components, concentrating on off-the-shelf capabilities for current and near future secondary side power generation and heat rejection as simulated in TRANSFORM. Generic models can be created which are agnostic of the nuclear energy supply without violating intellectual property rights of the developer. These models can be used to make informed decisions on the economics of integrating various energy system components with nuclear plant designs. Once complete, conclusions may be drawn regarding (1) the economics, efficiency, and reliability of certain nuclear reactors, (2) certain industry processes and energy storage systems, and (3) prioritization of certain reactor types with the studied industry types.
\end{abstract}

\title{
1. INTRODUCTION
}

Integrated energy systems (IESs) are "cooperatively-controlled systems that dynamically apportion thermal and/or electrical energy to provide responsive generation to the power grid" using nuclear as a key heat generation source [1]. These systems focus on creating financial and technically synergistic partnerships among various energy producers and consumers. Naturally, a given IES is tailored to the specific application of interest and the market in which it resides. To achieve acceptable technical and economic performance, various subsystem designs, integration options, and deployment scenarios must be evaluated. However, three general categories are considered for IES architectures as identified in the DOE-NE IES Program 2020 Roadmap [1].

1. tightly coupled IES - Thermally and electrically coupled, and co-controlled system.

2. thermally coupled IES - Subsystems are only coupled via thermal energy networks and cocontrolled to manage thermal demands; electrical needs are indirectly met via connections to the grid.

3. Loosely coupled, electricity-only IES - Subsystems are only coupled via electrical energy networks and are co-controlled to manage electricity demands.

For the purpose of comparison, the parameters of the balance-of-plant systems will be used to define plants with thermodynamic properties in line with IES architectures 1 and 2 . These IES architectures can shift to coproduction when demand is low and back to full electricity output when additional energy is needed on the grid. This approach requires power production systems that meet the following criteria: 
- Capable of diverting some or all thermal energy to a secondary storage or industrial production system

- Capable of safely running at a full or partial power level while diverting energy to systems not designed for the baseload power production

- Capable of redirecting stored energy back onto the grid from a storage source

- Capable of bringing a plant quickly back to maximum grid power in a short period of time

In an optimal IES, a thermal heat source would be able to quickly adapt to both grid demand and industrial demand simultaneously and instantaneously. This is an idealized system: a real-world scenario would require a nuclear power plant to ramp as quickly as possible to meet demand, typically at $\geq 5 \%$ rated thermal power per minute. The nature of the current nuclear fleet does not meet this criterion, because removing a turbine from power production can require hours of down time, and slow ramp rates can translate to days to achieve $100 \%$ power. By (1) identifying plants that can meet the power production criteria above and (2) having systems adaptable to IES architectures 1 and 2, IESs can be further developed, investigated, optimized, and realized for future projects.

\section{ENERGY CO-PRODUCTION TYPES}

The challenging nature of the energy market has required the nuclear power sector to compete with inexpensive, subsidized natural gas, solar, and wind power production. Historically, nuclear power has provided the baseload power and high capacity factors without load following, but production from other energy sources under the existing energy market conditions has driven down the price per $\mathrm{kWh}$ to below economical levels at which nuclear power can compete [5]. This has led many plants to investigate other methods for operating nuclear plants beyond providing baseload power. The design of pressurized water reactor (PWR) and boiling water reactor (BWR) fleets in the United States (US) has been based on the use of nuclear energy as baseload, whereas other countries such as France have conducted load follow with nuclear energy.

Because of the high capital costs to build nuclear plants and the low cost to maintain them at $100 \%$ operation, nuclear plants are most efficient for power production and economics when they provide $100 \%$ baseload power with high capacity factors. Beyond the use of advanced nuclear reactors for load following on the grid, there is additional interest in using nuclear plants to provide energy storage or heat to industrial processes to generate additional revenue for nuclear plants using high temperatures (500 to $600^{\circ} \mathrm{C}$ ). These temperatures are typically difficult to reach by other heating methods without burning fossil fuels, but they can be reached using certain advanced nuclear reactor concepts. Energy storage can also allow for faster response if the plant needs to load follow. Because ramping a turbine from 0 to $100 \%$ power level can take time, the diversion of a percentage of thermal energy away from the power generation cycle could allow the turbine to run at a lower energy rating, thus maintaining the lowest amount of power and temperature necessary to ramp up quickly when power is needed without the delays caused by taking a turbine offline and having to warm and restart.

Forsberg [5] chaired a workshop to investigate the economic environment that challenges the operation of the current nuclear reactor fleet and to analyze the potential energy storage options available. These options are also applicable to advanced reactors. The energy storage (ES) options are summarized below:

ES1. A steam accumulator is a pressure vessel heated to high pressure and high temperature that will be released to a turbine to produce electricity. 
ES2. A sensible heat fluid system heats a secondary fluid with steam at atmospheric pressure and then uses that fluid to provide heat at a later time, when economics are more favorable.

ES3. A cryogenic air system stores energy by liquifying air.

ES4. A packed-bed thermal energy storage system stores energy by heating pebbles with steam at pressure.

ES5. In a hot rock storage system, hot air is passed through crushed rock or other material to store heat.

ES6. In a geothermal heat storage systems, hot water or steam is injected into an underground reservoir for storage.

Thermal storage systems ES1 through ES6 require additional means for operating with a specific plant. For instance, each of these systems would need (1) a loop that could remove heat from the various primary or secondary loops to thermal storage, and (2) the proper storage facilities or geography to facilitate the storage medium. Storage could be added to the design, or an advanced reactor's inherent design could be used for storage without adding another system.

The economics of advanced reactors can also be improved by using a plant's primary, secondary, or waste heat for industrial processes. A report by the Joint Institute for Strategic Energy Analysis [6] describes the various industrial processes that lead to the majority of $\mathrm{CO}_{2}$ emissions in the United States. The report concludes that these industrial processes could utilize a nuclear reactor in co-production mode in which both electricity and process heat are required. Table 3.1-1 summarizes industrial processes in which advanced reactors with small footprints can be used instead of fossil fuel [6]. These selections can be made based on the maximum process heat temperature needed.

Table 3.1-1 shows the highest process temperatures necessary for each industrial process using fossil fuels. Processes with lower temperature are often used at each facility. Currently, some processes requiring higher temperatures use waste gases or heat from other exothermic process steps and do not need heat from another external source. However, small, advanced reactors could be used to reduce the plant's carbon emissions.

The items given in Table 3.1-1 can be categorized into Tier 1 , for high temperature needs $\left(>900^{\circ} \mathrm{C}\right)$, Tier 2 for mid-range temperature needs $\left(900^{\circ} \mathrm{C} \geq \mathrm{T}>600^{\circ} \mathrm{C}\right)$, which approach temperatures currently possible with reactor technologies, and Tier 3 for temperature needs $\left(<600^{\circ} \mathrm{C}\right)$. An IES is intended to prevent the use of fossil fuels and thus reduce or eliminate the $\mathrm{CO}_{2}$ production from burning fossil fuels to reach these process temperatures. Lower temperatures could be provided to processes in a preheat mode and would only use other means to "top off" the necessary heat for the industrial process step. This would reduce $\mathrm{CO}_{2}$ emission levels for these industries. As stated in the report from the Joint Institute for Strategic Energy Analysis, "In 2014, 960 plants representing these industries reported emissions under the GHGRP. They constitute less than $0.5 \%$ of all U.S. manufacturing facilities but are responsible for nearly $25 \%$ of U.S. GHG inventory industrial-sector emissions" [6]. A total of 643,451 marketable US manufacturing businesses are reported to the North American Industry Classification System (NAICS) database by February 2021[10], and the Greenhouse Gas Reporting Program (GHGRP) indicates a similar number of plants reporting greenhouse gas emissions in 2014 vs. 2019 [11]. The conclusions presented in the Joint Institute for Strategic Energy Analysis report [6] are still applicable. 
Table 3.1-1. Industrial process maximum temperature summary [6]

\begin{tabular}{clr}
\hline Industry ID & \multicolumn{1}{c}{ Target industry } & $\begin{array}{c}\text { Highest process } \\
\text { temperature using } \\
\text { fossil fuels } \\
{\left[{ }^{\circ} \mathbf{C}\right]}\end{array}$ \\
\hline IP1 & Iron and steel mills & 2,200 \\
IP2 & Lime & 1,500 \\
IP3 & Cement & 1,500 \\
IP4 & Basic chemical manufacturing & 900 \\
IP5 & Petrochemical manufacturing & 875 \\
IP6 & Nitrogenous fertilizer manufacturing & 850 \\
IP7 & Pulp mills & 800 \\
IP8 & Petroleum refineries (gasoline, diesel, kerosene) & 600 \\
IP9 & Potash, soda and borate mining & 300 \\
IP10 & Plastics and material and resin manufacturing & 291 \\
IP11 & Ethyl alcohol manufacturing & 266 \\
IP12 & Alkalis, chlorine, and sodium hydroxide manufacturing & 177 \\
IP13 & Starch, corn gluten feed, corn gluten meal, corn oil & 177 \\
& manufacturing & 150 \\
IP14 & Paper mills & 150 \\
IP15 & Paperboard mills & 50 \\
IP16 & Wet corn milling & \\
\hline
\end{tabular}

To have a coupled system, the industrial plant in question must have one of two key features depending on its operating conditions and design. The first key feature is that the plant would need to have a system to transfer heat to an industrial process rather than its primary power production cycle, which in turn would likely reduce the overall efficiency of the plant. The second key feature that could exist is excess heat due to a low thermal efficiency of the plant, where instead of this heat being rejected to the environment it can be applied to a secondary process or general thermal storage capacity. High steam or heat transfer media temperature, combined with the low thermal efficiency of the system, results in a higher thermal load that can be provided to a secondary process.

Secondary features would be related to other considerations, such as the size of the plant. These features would determine how much process or storage heat can be provided, as well as plant location.

\section{GENERATION IV ADVANCED REACTOR TYPES}

The advanced reactor design market is highly diverse, and design approaches are often novel given the maturity of the advanced reactor industry. The variety of advanced reactors is due to limited operating experience, data, regulatory scrutiny, and limited construction experience. These factors when combined with economic pressures of the market typically lead an industry towards more reliable and inexpensive practices. Once data from experiments or deployment of an advanced reactor are complete it can be expected that many of the highly diverse designs will alter towards the practices proven to be effective. Until the industry standards are established, plants that can be grouped together in a similar category may often have very different features, fuels, and operating parameters. Therefore, a plant may fit into several different categories and is highly likely to have its design changed in the future. To sort and compare the widely variable plant designs for Generation IV Advanced reactors, categories of plants were defined to 
correspond with the International Atomic Energy Agency (IAEA) Advanced Reactors Information System (ARIS) Database [2]. The ARIS categories are listed below:

1. PWR - pressurized water reactor

2. BWR - boiling water reactor

3. HWR - heavy water reactor

4. SCWR - supercritical-water reactor

5. iPWR - integral pressurized water reactor

6. GCR - gas-cooled reactor

7. GFR - gas-cooled fast reactor

8. SFR - sodium-cooled fast reactor

9. LFR - lead-cooled fueled fast reactor

10. MSR - molten salt reactor

11. SMR - small modular reactor

Based on this criteria, types 1 through 5 will not be evaluated because they utilize water as the primary moderator and coolant; the purpose of this paper is to focus on advanced reactors that utilize other coolants. Categories are typically based on reactor core designs, fuel, or cooling medium. However, reactor type 11, the small modular reactor (SMR), is based on reactor core size and a modular manufacturing concept. The SMRs under development typically fit within the other categories, so for the purposes of this paper, these will be grouped with those designs instead of in an SMR. It should be noted that the SCWR concept, while being a light water reactor and beyond the considered scope of this document, is a highly efficient conceptual plant design with three proposed reactors and may be a point of consideration in the future.

Literature searches for advanced reactor designs and review of the Generation IV International Forum [4] show that the IAEA database [1] and the Third Way [3] reports address the largest collection of plants. This search was augmented with other literature searches independent of these sites. A primary source for advanced reactor development in the United States was been published by Third Way [3]. These sources were combined to include as many designs as possible. This list may not comprise all reactors currently under development. In each category, the general technological readiness level (TRL) is evaluated to indicate how long it could take to deploy such technologies. The TRL scale ranges from 1-9, where 9 is considered a proven design, and 1 has the basic principles observed and reported with minimal validation. Most technologies under design and development with minimal prototyping have TRLs in a range of 1-5.

\subsection{GAS-COOLED REACTORS}

As defined by the ARIS database, gas-cooled reactors utilize graphite as the neutron moderator, whereas the fluid medium for cooling is carbon dioxide or helium. They are the only type of reactor considered in this report having similar plants operating in the United Kingdom that are used for power generation and various industrial applications. However, despite this technology having been deployed for commercial use for US deployment, the TRL is considered a 5 for US deployment [8].

As shown in Table 3.1-1, the results yielded 10 reactors of this type in various stages of design. 
Table 3.1-1. Gas-cooled reactors

\begin{tabular}{|c|c|c|c|c|c|c|c|}
\hline Abbreviation & Full name & Design Organization & Coolant & Moderator & Design status & Country & Purpose \\
\hline GTHTR300C & $\begin{array}{c}\text { Gas turbine high temperature } \\
\text { reactor }\end{array}$ & $J A E A$ & Helium & Graphite & $\begin{array}{l}\text { Conceptual } \\
\text { design }\end{array}$ & Japan & Demonstration \\
\hline GT-MHR & $\begin{array}{l}\text { Gas turbine, modular helium } \\
\text { cooled reactor }\end{array}$ & General Atomics & Helium & Graphite & Under design & USA & Commercial \\
\hline Holos & Holos generator & Holosgen & $\begin{array}{l}\text { Helium or } \\
\quad \mathrm{CO}_{2}\end{array}$ & Graphite & $\begin{array}{l}\text { Conceptual } \\
\text { design }\end{array}$ & $U S A$ & Commercial \\
\hline$H T R-P M$ & $\begin{array}{l}\text { High temperature GCR - pebble- } \\
\text { bed module }\end{array}$ & Tsinghua University & Helium & Graphite & Construction & China & Demonstration \\
\hline$M M R$ & Micro modular reactor & MMR Energy Systems & Helium & Graphite & Under design & $U S A$ & Commercial \\
\hline NGNP & Next Generation nuclear plant & Idaho National Lab & Helium & Graphite & Under design & USA & Demonstration \\
\hline$P B M R$ & Pebble bed modular reactor & $\begin{array}{l}\text { Pebble Bed Modular } \\
\text { Reactor (Pty) Limited }\end{array}$ & Helium & Graphite & On hold & $\begin{array}{l}\text { South } \\
\text { Africa }\end{array}$ & Commercial \\
\hline$S C-H T G R$ & $\begin{array}{c}\text { Steam cycle high temperature gas- } \\
\text { cooled reactor }\end{array}$ & Framatome & Helium & Graphite & $\begin{array}{l}\text { Conceptual } \\
\text { design }\end{array}$ & $U S A$ & Commercial \\
\hline Starcore & - & Starcore Nuclear & Helium & - & - & Canada & - \\
\hline$X e-100$ & $X e-100$ & $X$-Energy & Helium & Graphite & Under design & $U S A$ & Commercial \\
\hline
\end{tabular}

Items in italics are considered SMRs 


\subsubsection{Gas-Cooled Reactors: Primary Description}

Gas-cooled reactors (GCR) utilize helium or a noble gas mixture (such as $\mathrm{He}-\mathrm{Xe}$ ) as the primary side coolant and either $\mathrm{CO}_{2}$ or water as the secondary side working medium if a direct cycle is not used. In the typical design, the primary side coolant gas is passed through a core with encapsulated fuel in some form - typically pebbles or fuel channels. Neutrons are moderated by graphite into the thermal spectrum which delineates this reactor type from Gas-cooled fast reactors. Reactor cores are often designed to refuel online and to cycle out the fuel regularly to maintain a high-capacity factor and eliminate long refueling outages. Core outlet temperatures range from 750 to $850^{\circ} \mathrm{C}$, with projected core temperature increases of $250^{\circ} \mathrm{C}$ to $500^{\circ} \mathrm{C}$. Upon exiting the core, the cooling medium is passed through a power generation cycle; this part of the process is highly dependent on the design.

One item that illustrates the variation available in advanced reactor designs of this type is the selection of fuel type for the reactor. The GTHTR300C fuel utilizes a pin-in-block design with tristructural isotropic (TRISO) fuel pebbles stacked in 12 fuel compacts which are placed in a fuel rod without an outer sleeve. The rod is surrounded by a graphite moderator. The HTR-PM is a gas-cooled pebble bed reactor that feeds 420,000 fuel element TRISO pebbles into a cylindrical reactor 3 meters in diameter and 11 meters high. The HTR-PM can cycle out these fuel element pebbles, analyze them, and then reinsert them. The GTHTR300C design does not have a secondary loop; instead, it utilizes a gas turbine and primary loop only via a Brayton cycle instead of passing heat to a secondary loop. The HTR-PM passes the heated gas through a heat exchanger to a secondary loop and relies on a standard water Rankine cycle to generate power. The HTR-PM's general design scheme is more common for this type of reactor. The primary similarities between these two designs are the gas coolant, graphite moderation of neutrons to the thermal energy spectrum, and their high-temperature primary side output. Beyond these similarities, the two designs described here illustrate the highly diverse nature of GCR designs.

Table 3.1-2. Gas-cooled reactor primary reactor system parameter summary

\begin{tabular}{lcccccc}
\hline Abbreviation & $\begin{array}{c}\text { Primary } \\
\text { coolant } \\
\text { flow rate } \\
{[\mathbf{k g} / \mathbf{s}]}\end{array}$ & $\begin{array}{c}\text { Reactor } \\
\text { operating } \\
\text { pressure } \\
{[\mathbf{M P a}]}\end{array}$ & $\begin{array}{c}\text { Coolant inlet } \\
\text { temperature } \\
{\left[{ }^{\circ} \mathbf{C}\right]}\end{array}$ & $\begin{array}{c}\text { Coolant } \\
\text { outlet } \\
\text { temperature } \\
{\left[{ }^{\circ} \mathbf{C}\right]}\end{array}$ & $\begin{array}{c}\text { Delta } \\
\text { temperature } \\
{\left[{ }^{\circ} \mathbf{C}\right]}\end{array}$ & $\begin{array}{c}\text { Reactor } \\
\text { thermal } \\
\text { output } \\
{[\mathbf{M W t h}]}\end{array}$ \\
\hline GTHTR300C & 439 & 7 & 587 & 850 & 263 & 600 \\
GT-MHR & 320 & 7.07 & 491 & 850 & - & 600 \\
Holos & - & - & - & - & - & - \\
HTR-PM & 96 & 7 & 250 & 750 & 500 & 500 \\
MMR & 8.8 & 3 & - & 630 & - & 15 \\
NGNP & - & - & - & $>1000$ & - & - \\
PBMR & 96 & 6 & 250 & 750 & 500 & 400 \\
SC-HTGR & - & 6 & 325 & 750 & 425 & 625 \\
Starcore & - & - & - & - & - & 36 \\
Xe-100 & - & 7 & - & 750 & - & 200 \\
\hline
\end{tabular}

Items in italics are considered SMRs; listed values are for the minimum reactor amount only.

\subsubsection{Gas-Cooled Reactors: Secondary Description}

The secondary side balance of plant for this category of reactors can achieve steam temperatures at pressures greater than $10 \mathrm{MPa}$ over $500^{\circ} \mathrm{C}$ utilizing both Brayton and Rankine cycles, although the 
designs listed at present favor a primary and secondary loop with a helium-to-water steam generator and a Rankine thermodynamic cycle. The ability to obtain such high temperatures at pressure leads to higher efficiency ratings of the plant, typically $>40 \%$ net efficiency. This is important, because syphoning off heat for industrial processes, energy storage, or hydrogen production typically reduces the efficiency of power generation. However, since this practice has a large net efficiency, it can also result in reduced residual waste heat to use in these processes. Net power output for these plants ranges from 80 to 272 MWe, with scaling options for several designs to potentially go to higher power levels or to have several primary system modules coupled to a power generation secondary system, thus showing the general design trends toward smaller, more flexible, compact designs. Many reactor types advertise their ability to scale up or down in power and size to meet a customer's need in addition to adding modules.

For five of the reactor types shown in Table 3.1-3, their thermodynamic cycle is specified as a Rankine cycle, and two list a Brayton cycle as their power production loop cycle. Four of the reactor types do not specify their cycle type in the reactor descriptions. The TRL for a Brayton cycle is higher than the standard Rankine cycle, and thus may push many GCR designs away from a using a single closed Brayton cycle for their plant due to the potential increased research and development costs and risk in using the lower TRL technology.

Table 3.1-3. Gas-cooled reactor secondary system parameter summary

\begin{tabular}{lccccc}
\hline Abbreviation & $\begin{array}{c}\text { Steam flow } \\
\text { rate } \\
{[\mathbf{k g} / \mathbf{s}]}\end{array}$ & $\begin{array}{c}\text { Steam pressure } \\
{[\mathbf{M P a}]}\end{array}$ & $\begin{array}{c}\text { Steam } \\
\text { temperature } \\
{\left[{ }^{\circ} \mathbf{C}\right]}\end{array}$ & $\begin{array}{c}\text { Feedwater flow } \\
\text { rate } \\
{[\mathbf{k g} / \mathbf{s}]}\end{array}$ & $\begin{array}{c}\text { Feedwater } \\
\text { temperature } \\
{\left[{ }^{\circ} \mathbf{C}\right]}\end{array}$ \\
\hline GTHTR300C & - & - & - & - & - \\
GT-MHR & 320 & 7.01 & $848 / 511$ & - & - \\
Holos & - & - & - & - & - \\
HTR-PM & 186.39 & - & 566 & - & - \\
MMR & - & - & - & - & - \\
NGNP & - & - & - & - & - \\
PBMR & 195 & 12 & 540 & - & 200 \\
SC-HTGR & - & 16 & - & - & - \\
Starcore & - & - & - & - & - \\
$X e-100$ & - & 16.5 & 565 & - & - \\
\hline
\end{tabular}

Items in italics are considered SMRs; listed values are for the minimum reactor amount only.

Note that GTHTR300C and GT-MHR have no secondary system because it is a closed single loop power generation Brayton Cycle. The pebble bed modular reactor (PBMR) also includes this feature as one of their possible designs.

\subsubsection{Gas-Cooled Reactor Summary}

The high temperature and high efficiency of the GCR category of plants makes it ideal for inclusion in any IES. High-temperature steam production and primary side helium can be coupled with additional heat transfer loops to allow for thermal storage capabilities ES1 through ES6. One plant in particular, the micro modular reactor (MMR), has a published brochure that lists thermal storage, process heat, and desalination as non-electrical capabilities, although the details on a fleshed-out design for the IES are minimal. 
Table 3.1-4. GCR Plant Overview Summary

\begin{tabular}{|c|c|c|c|c|c|}
\hline Abbreviation & $\begin{array}{c}\text { Reactor } \\
\text { thermal } \\
\text { output } \\
\text { [MWth] }\end{array}$ & $\begin{array}{c}\text { Power plant } \\
\text { output, } \\
\text { gross } \\
\text { [MWe] } \\
\end{array}$ & $\begin{array}{l}\text { Power plant } \\
\text { output, net } \\
\text { [Mwe] }\end{array}$ & $\begin{array}{c}\text { Plant } \\
\text { efficiency, net } \\
{[\%]}\end{array}$ & Non-electrical applications \\
\hline GTHTR300C & 600 & 274 & - & 47.7 & H2 production \\
\hline GT-MHR & 600 & - & 286 & - & - \\
\hline Holos & - & - & - & - & - \\
\hline$H T R-P M$ & 500 & 211 & 200 & - & - \\
\hline$M M R$ & 15 & - & - & - & $\begin{array}{c}\text { Molten salt thermal storage, process } \\
\text { heat, desalinization }\end{array}$ \\
\hline NGNP & - & - & - & - & - \\
\hline$P B M R$ & 400 & - & 165 & 40 & - \\
\hline$S C-H T G R$ & 625 & 282 & 272 & 43 & Industrial process heat \\
\hline Starcore & 36 & - & - & - & - \\
\hline$X e-100$ & 200 & - & 80 & - & - \\
\hline
\end{tabular}

Items in italics are considered SMRs; listed values are for the minimum reactor amount only.

Due to the high efficiency ratings for these designs, there is limited opportunity to capture waste heat for use in industrial processes when compared to other nuclear reactor types. For an industrial process or energy storage system to be able to use the high temperatures produced by GCRs, the thermal energy must be diverted before it enters the turbine, whereas lower temperatures could be provided after the turbines for low temperature process needs.

The use of a closed loop Brayton cycle adds efficiency and simplicity to the design, but it requires additional heat exchangers or systems to properly couple with storage systems. For plants using a Rankine cycle, the steam system can be used for storage systems ES1-ES3 most efficiently. The closed systems would work best with the ES3 type of energy storage, followed by ES1, ES2, and ES4. ES5 and ES6 storage systems are based on the site location and the necessary geological landscape for efficiency. The differences are due to the need to add a secondary heat exchanger to the primary loop for cases in which one may not exist, adding cost to the design.

Generally, the gas-cooled reactor designs specified here can provide temperatures high enough to provide process heat for all industrial processes listed in Table 3.1-1. Because GCRs produce the highest primary temperature of all the nuclear plant types reviewed, they are the best fit for industrial processes IP1 to IP8. Additionally, helium is not corrosive and will not interact with the chemicals used in many industrial processes, making it ideal for use in an industrial park that requires the coolant to travel a longer distance or to feed additional processes. This is also useful for coupling with a hydrogen production plant on or near the site.

The GT-MHR Conceptual Design, developed by General Atomics [9], contains significant detail regarding reporting to the US Nuclear Regulatory Commission (NRC). The current version of the design at this writing does not present a non-electrical application, so it could be a prime candidate to be analyzed for inclusion in an IES.

\subsection{GAS-COOLED FAST REACTOR}

Gas-cooled fast reactors are very similar to the gas-cooled reactors defined in Section 3.1. Since gascooled fast reactors utilize fast neutrons instead of thermalized neutrons, the primary difference for this 
type of reactor is removal of the graphite moderator from the reactor or fuel. Significant research and development are needed for these types of reactors: the TRL for deployment is considered 2 [8]. This means that the development timescale for deployment in the United States could be $>20$ years. However, like other gas-cooled reactors, gas-cooled fast reactors have very high-power conversion loop steam temperatures, which is beneficial for secondary processes other than power generation.

Table 3.2-1. Gas-cooled fast reactors

\begin{tabular}{|c|c|c|c|c|c|c|c|}
\hline Abbreviation & Full name & Design Org. & Coolant & Moderator & Design status & Country & Purpose \\
\hline ALLEGRO & ALLEGRO & EURATOM & Helium & No Moderator & Pre-Conceptual & EU & Demonstration \\
\hline$E M 2$ & $\begin{array}{l}\text { Energy } \\
\text { Multiplier } \\
\text { Module }\end{array}$ & $\begin{array}{l}\text { General } \\
\text { Atomics }\end{array}$ & Helium & No Moderator & $\begin{array}{l}\text { Conceptual } \\
\text { Design }\end{array}$ & $U S A$ & Commercial \\
\hline GFR2400 & $\begin{array}{l}\text { Gas-Cooled } \\
\text { Fast Reactor }\end{array}$ & $\begin{array}{c}\text { European FP7 } \\
\text { GoFastR }\end{array}$ & Helium & No Moderator & $\begin{array}{l}\text { Conceptual } \\
\text { Design }\end{array}$ & EU & Commercial \\
\hline $\begin{array}{l}\text { KAMADO } \\
\text { FBR }\end{array}$ & $\begin{array}{l}\text { KAMADO } \\
\text { FBR }\end{array}$ & CREIPI & $\mathrm{CO} 2$ & No Moderator & $\begin{array}{l}\text { Conceptual } \\
\text { Design }\end{array}$ & Japan & Demonstration \\
\hline
\end{tabular}

Items in italics are considered SMRs; listed values are for the minimum reactor amount only.

\subsubsection{GFR Primary Loop System Characterization}

Gas-cooled fast reactors follow a primary reactor loop design like that of standard thermal neutron gascooled reactors, except they the graphite moderator is removed and replaced with the TRISO fuel portion that contains $\mathrm{U}_{235}$ or mixed oxide (MOX) fuel assemblies of higher enrichments than that of current light water reactors (LWRs) (5\%). Additional fuel types could be used that can convert between fissionable to fissile material in a fast neutron spectrum. Heat from the fuel assemblies would be dissipated with an inert gas. Helium or $\mathrm{CO}_{2}$ would either be passed through a gas turbine or transferred to a secondary loop. This reactor type is capable of using a Brayton or Rankine cycle for power conversion and can also obtain high output temperatures in the range of 400 to $850^{\circ} \mathrm{C}$, similar to gas-cooled reactors. Therefore, this reactor type can support a higher efficiency rating. The KAMADO fast breeder reactor (FBR) concept implements a water pool along the outside of the reactor core to generate high-temperature steam from gamma radiation. This steam would be used to feed secondary processes such as hydrogen production.

Table 3.2-2. Gas-cooled fast reactor primary system parameter summary

\begin{tabular}{lcccccc}
\hline Abbreviation & $\begin{array}{c}\text { Primary } \\
\text { coolant flow } \\
\text { rate } \\
{[\mathbf{k g} / \mathbf{s}]}\end{array}$ & $\begin{array}{c}\text { Reactor } \\
\text { operating } \\
\text { pressure } \\
{[\mathbf{M P a}]}\end{array}$ & $\begin{array}{c}\text { Coolant inlet } \\
\text { temperature } \\
{\left[{ }^{\circ} \mathbf{C}\right]}\end{array}$ & $\begin{array}{c}\text { Coolant outlet } \\
\text { temperature } \\
{\left[{ }^{\circ} \mathbf{C}\right]}\end{array}$ & $\begin{array}{c}\text { Delta } \\
\text { temperature } \\
{\left[{ }^{\circ} \mathbf{C}\right]}\end{array}$ & $\begin{array}{c}\text { Reactor } \\
\text { thermal } \\
\text { output } \\
{[\mathbf{M W t h}]}\end{array}$ \\
\hline ALLEGRO & - & - & 260 & 530 & 270 & 75 \\
EM2 & 320 & 13 & 550 & 850 & 300 & 500 \\
GFR2400 & 1213 & 77 & 400 & 780 & - & 2,400 \\
KAMADO FBR & - & 15 & 200 & 400 & 200 & 3,000 \\
\hline
\end{tabular}

Items in italics are considered SMRs; listed values are for the minimum reactor amount only.

\subsubsection{GFR Secondary Loop System Characterization}

Like gas-cooled reactors that utilize thermalized neutrons and a moderator, the secondary designs of gascooled fast reactors can either have a secondary system for power generation, or they can have an inert 
gas closed loop system with turbine contained in the primary loop. There is little information available about the four nuclear reactors currently under design regarding the power conversion loop for their reactor cores. General artist renderings and basic details gathered from the literature search indicate that these plants will have closed loop combined or Brayton cycles, except for the KAMADO FBR design, for which Rankine is specified, with no additional details. However, the thermodynamic cycles are not specified, so this could be changed during the design phase. Due to the lack of sufficient design details, this reactor type cannot be properly modeled based on available information.

\subsubsection{GFR Summary}

The GFR concepts and system parameters are similar to those of GCR reactors, so the same conclusions are drawn as stated in Section 3.1.3. Details for the EM2 and KAMADO FBR stipulate that the reactors could be used for commercial power, as well as secondary industrial services such as hydrogen production, desalination, and other industrial processes in line with IES goals. The EM2 reactor is a smaller modular design meant to be used as more than 1 reactor core $(\leq 4)$, with a net efficiency of $\sim 53 \%$. The KAMADO FBR is designed for scalable reactor powers ranging from 1,000 to 3,000 MWt at an assumed efficiency rating of 33\%. Both of these concepts - small and modular and the water pool for hydrogen production (discussed in Section 3.2.1) — fit well with the IES philosophy.

Table 3.2-3. GFR plants overview

\begin{tabular}{lccccc}
\hline Abbreviation & $\begin{array}{c}\text { Reactor } \\
\text { thermal output } \\
\text { [MWth] }\end{array}$ & $\begin{array}{c}\text { Power plant } \\
\text { output, gross } \\
\text { [MWe] }\end{array}$ & $\begin{array}{c}\text { Power plant } \\
\text { output, net } \\
\text { [Mwe] }\end{array}$ & $\begin{array}{c}\text { Plant } \\
\text { efficiency, net } \\
{[\%]}\end{array}$ & $\begin{array}{c}\text { Non-electrical } \\
\text { applications }\end{array}$ \\
\hline ALLEGRO & 75 & - & - & - & - \\
EM2 & 500 & 272 & 265 & 53 & $\begin{array}{c}\text { Desalinization, hydrogen } \\
\text { production }\end{array}$ \\
GFR2400 & - & - & - & - & - \\
KAMADO FBR & 3,000 & 1,000 & 1,000 & 33.3 & Hydrogen production \\
\hline
\end{tabular}

Items in italics are considered SMRs; listed values are for the minimum reactor amount only.

Because they are similar, the same conclusions for process and energy storage usage of thermal energy from GCRs apply to GFRs.

\subsection{SODIUM-COOLED FAST REACTORS}

Sodium-cooled fast reactors are a primary topic of research and development in the United States, partially spurred on by the available data and operational experience obtained from the Experimental Breeder Reactor II (EBR-II) and the Enrico Fermi power plant in Michigan, both of which produced electricity. Because of these experiments and the additional research in the area of this plant type, the TRL is slightly higher than for other designs, ranging from 3 for novel or experimental designs to 5 for designs that duplicate EBR-II and Fermi designs [8]. These types of reactors produce high temperatures on the primary and secondary sides, and they also have the ability to burn MOX fuel. The sodium coolant has passive safety aspects, as well. However, these types of plants experience corrosion due to the use of a molten sodium as the fluid medium, as well as high dose rates due to the use of a fast energy spectrum. Furthermore, the reaction that may occur with water must be mitigated. The primary mitigation measure is to add multiple heat transfer loops, replacing the fluid medium with a medium that is not highly reactive to water. This helps to avoid potential reactions with the power production loop, which contains water and steam. 
Table 3.3-1. Sodium-cooled fast reactors

\begin{tabular}{|c|c|c|c|c|c|c|c|}
\hline Abbreviation & Full name & Design Organization & Coolant & Moderator & Design Status & Country & Purpose \\
\hline $4 S$ & $\begin{array}{l}\text { super-safe, small and } \\
\text { simple }\end{array}$ & $\begin{array}{l}\text { Toshiba Energy Systems \& } \\
\text { Solutions Corp. }\end{array}$ & Sodium & $\begin{array}{c}\text { No } \\
\text { moderator }\end{array}$ & Detailed design & Japan & Commercial \\
\hline AFR-100 & Advanced Fast Reactor & $\begin{array}{l}\text { Argonne National } \\
\text { Laboratory }\end{array}$ & Sodium & $\begin{array}{l}\text { No } \\
\text { moderator }\end{array}$ & Under design & USA & Demonstration \\
\hline$A R C-100$ & $\begin{array}{l}\text { Advanced Reactor } \\
\text { Concepts }\end{array}$ & $\begin{array}{l}\text { Advanced Reactor } \\
\text { Concepts }\end{array}$ & Sodium & $\begin{array}{c}\text { No } \\
\text { moderator }\end{array}$ & Under design & $U S A$ & Commercial \\
\hline ASTRID & $\begin{array}{c}\text { Advanced Sodium } \\
\text { Technological Reactor } \\
\text { for Industrial } \\
\text { Demonstration }\end{array}$ & $C E A$ & Sodium & $\begin{array}{c}\text { No } \\
\text { moderator }\end{array}$ & Under design & France & Demonstration \\
\hline $\mathrm{BN}-1200$ & $\mathrm{BN}-1200$ & JSC “Afrikantov OKBM” & Sodium & $\begin{array}{l}\text { No } \\
\text { moderator }\end{array}$ & Construction & Russia & Commercial \\
\hline CFR-600 & China Fast Reactor 600 & $\begin{array}{c}\text { China Institute of Atomic } \\
\text { Energy }\end{array}$ & Sodium & $\begin{array}{c}\text { No } \\
\text { moderator }\end{array}$ & $\begin{array}{l}\text { Conceptual } \\
\text { Design }\end{array}$ & China & Demonstration \\
\hline$F B R-1 \& 2$ & $\begin{array}{l}\text { Fast Breeder } \\
\text { Reactors } 1 \& 2\end{array}$ & $I G C A R$ & Sodium & $\begin{array}{c}\text { No } \\
\text { moderator }\end{array}$ & Under design & India & Commercial \\
\hline JSFR & $\begin{array}{c}\text { Japan Sodium-Cooled } \\
\text { Fast Reactor }\end{array}$ & JAEA & Sodium & $\begin{array}{l}\text { No } \\
\text { moderator }\end{array}$ & Under design & Japan & Commercial \\
\hline MBIR & $\begin{array}{l}\text { Multipurpose fast- } \\
\text { neutron research reactor }\end{array}$ & NIKIET & Sodium & $\begin{array}{l}\text { No } \\
\text { moderator }\end{array}$ & Under design & Russia & Experimental \\
\hline PGSFR & $\begin{array}{c}\text { Prototype Gen-IV } \\
\text { Sodium-cooled Fast } \\
\text { Reactor }\end{array}$ & KAERI & Sodium & $\begin{array}{l}\text { No } \\
\text { moderator }\end{array}$ & Conceptual design & $\begin{array}{l}\text { Rep. of } \\
\text { Korea }\end{array}$ & Demonstration \\
\hline PRISM & $\begin{array}{c}\text { Power Reactor } \\
\text { Innovative Small Reactor }\end{array}$ & GE-Hitachi & Sodium & $\begin{array}{c}\text { No } \\
\text { moderator }\end{array}$ & Under design & $U S A$ & Commercial \\
\hline TWR-P & $\begin{array}{l}\text { Travelling Wave } \\
\text { Reactor-Prototype }\end{array}$ & TerraPower & Sodium & $\begin{array}{c}\text { No } \\
\text { moderator }\end{array}$ & Under design & USA & Commercial \\
\hline
\end{tabular}

Items in italics are considered SMRs; listed values are for the minimum reactor amount only. 


\subsubsection{Sodium-Cooled Fast Reactor Primary Loop System Characterization}

Sodium-cooled fast reactors rely on a fast neutron spectrum and liquid sodium as the reactor coolant. This allows for high power densities with a low coolant volume fraction. These types of reactors typically have two primary loop designs: loop type and pool type. In the loop type reactor, sodium is pumped from the reactor core through a sodium heat exchanger to the remaining balance of plant, while in the pool type reactor, the sodium in the reactor typically remains within the pool, and a secondary fluid (often a liquid salt) is pumped through a pool heat exchanger to transfer heat to the balance of plant. Since fast-spectrum neutrons are used to maintain the reactor, there is no moderator present in the reactor core, and the principal designs utilize MOX fuel for operation. The typical core outlet temperatures proposed based on the literature review range from 485 to $550^{\circ} \mathrm{C}$, and they operate at near atmospheric pressures. While the temperature range for sodium-cooled fast reactors is lower than that of gas-cooled reactors, the power density of the working fluid and the ability to burn MOX fuel could improve the economics of sodiumcooled fast reactors.

Table 3.3-2. Sodium-cooled fast reactor primary system parameter summary

\begin{tabular}{lcccccc}
\hline Abbreviation & $\begin{array}{c}\text { Primary } \\
\text { coolant } \\
\text { flow rate } \\
{[\mathbf{k g} / \mathbf{s}]}\end{array}$ & $\begin{array}{c}\text { Reactor } \\
\text { operating } \\
\text { pressure } \\
{[\mathbf{M P a}]}\end{array}$ & $\begin{array}{c}\text { Coolant } \\
\text { inlet } \\
\text { temperature } \\
{\left[{ }^{\circ} \mathbf{C}\right]}\end{array}$ & $\begin{array}{c}\text { Coolant outlet } \\
\text { temperature } \\
{\left[{ }^{\circ} \mathbf{C}\right]}\end{array}$ & $\begin{array}{c}\text { Delta } \\
\text { temperature } \\
{\left[{ }^{\circ} \mathbf{C}\right]}\end{array}$ & $\begin{array}{c}\text { Reactor } \\
\text { thermal } \\
\text { output } \\
{[\mathbf{M W t h}]}\end{array}$ \\
\hline $4 S$ & 152 & 0.2 & 355 & 510 & 155 & 30 \\
AFR-100 & - & 0.1 & 395 & 550 & 155 & 250 \\
ARC-100 & - & - & 355 & 510 & 155 & 260 \\
ASTRID & - & 0.3 & - & 475 & & 1500 \\
BN-1200 & - & 0.54 & 410 & 550 & 140 & 2800 \\
CFR-600 & - & 0.054 & 380 & 550 & 170 & 1500 \\
FBR-1 \& 2 & - & 0.11 & 397 & 547 & 150 & 1250 \\
JSFR & - & 0.15 & - & 550 & 550 & 3530 \\
MBIR & - & 0.6 & 330 & 512 & 182 & 150 \\
PGSFR & - & 0.1 & 390 & 545 & 155 & 150 \\
PRISM & 2293 & 0.1 & 337 & 485 & 485 & 840 \\
TWR-P & - & 0.1 & 360 & 500 & 140 & 1475 \\
\hline
\end{tabular}

Items in italics are considered SMRs; listed values are for the minimum reactor amount only.

\subsubsection{Sodium-Cooled Secondary Loop System Characterization}

One of the prime distinguishing features of a sodium-cooled reactor is that the balance of plant does not typically have a single secondary loop. Most designs contain an intermediary loop and a secondary power production loop. The purpose of this loop is to isolate the molten fuel that is contained in the primary salt medium while also providing a fission product barrio for isotopes such as tritium. This transfers heat to a final system that could use water or another medium. This secondary power production loop resembles the typical balance of plant used in other types of nuclear reactors. There is high interest in the use of supercritical $\mathrm{CO}_{2}\left(\mathrm{~S}-\mathrm{CO}_{2}\right)$ or other gas because it does not react with the sodium compounds if a heat exchanger ruptures. However, few reactors have specified $\mathrm{S}_{-} \mathrm{CO}_{2}$ for the secondary system. Two exceptions are the ARC-100 and ASTRID designs. The secondary thermodynamic cycles listed cover the Rankine and Brayton cycles, with the Rankine cycle being the dominant thermodynamic cycle of choice. 
Steam temperatures for the power production stage range from 453 to $530^{\circ} \mathrm{C}$. Table $3.3-3$ gives details on the information available from the literature search.

Table 3.3-3. Sodium-cooled fast reactor power production system parameter summary

\begin{tabular}{lccccc}
\hline Abbreviation & $\begin{array}{c}\text { Steam } \\
\text { flow rate } \\
{[\mathbf{k g} / \mathbf{s}]}\end{array}$ & $\begin{array}{c}\text { Steam } \\
\text { pressure } \\
{[\mathbf{M P a}]}\end{array}$ & $\begin{array}{c}\text { Steam } \\
\text { temperatur } \\
\mathbf{e} \\
{\left[{ }^{\circ} \mathbf{C}\right]}\end{array}$ & $\begin{array}{c}\text { Feedwater } \\
\text { flow rate } \\
{[\mathbf{k g} / \mathbf{s}]}\end{array}$ & $\begin{array}{c}\text { Feedwater } \\
\text { temperature } \\
{\left[{ }^{\circ} \mathbf{C}\right]}\end{array}$ \\
\hline $4 S$ & - & 10.8 & 453 & - & 210 \\
AFR-100 & - & 20 & 515.4 & - & - \\
ARC-100 & - & - & - & - & - \\
ASTRID & - & - & - & - & - \\
BN-1200 & - & 17 & 510 & - & 275 \\
CFR-600 & - & - & - & - & - \\
FBR-1 \& 2 & 195 & 18 & 450 & - & - \\
JSFR & - & - & - & - & - \\
MBIR & - & - & - & - & - \\
PGSFR & - & - & - & - & - \\
PRISM & 258 & 7 & 285 & - & - \\
TWR-P & - & - & - & - & - \\
\hline
\end{tabular}

Items in italics are considered SMRs; listed values are for the minimum reactor amount only.

\subsubsection{Sodium-Cooled Fast Reactor Summary}

Sodium-cooled fast reactors are more efficient than the pervasive LWRs operating in the world today, but their systems and basic designs resemble those of an LWR's usage and baseload power. Most designs presented in this section are designed to maintain $>600 \mathrm{MWe}$ outputs and do not advertise their flexibility to divert energy to other processes. While their power densities and ability to burn spent fuel actinides to increase cycle economics remain attractive, additional study of the sodium-cooled fast reactor designs is needed to determine their application to IESs to further improve fuel cycle economics. The only plant that considers a secondary use of energy is the $4 \mathrm{~S}$ small micro-reactor design, which is an outlier within this reactor type. A summary of the general plant parameters is listed in Table 3.3-4.

As evidenced here, very few reactors have listed a non-electric application. Despite having slightly lower net efficiencies then gas-cooled reactors, sodium-cooled fast reactor temperatures are comparable to those of other advanced reactor types and the potential for more waste heat or higher temperatures that can be used in a secondary industrial process.

The intermediary loop included in many of these designs provides an opportunity to couple them with energy storage systems. Because the second loop is often a less chemically reactive medium than the primary loop, the secondary loop is already established as an ES2 type of energy storage. Additional feed stock of the intermediary coolant could be injected into the secondary loop and syphoned off while reducing the power production loop's energy production. The remaining fluid could be placed into an energy storage position. Thus, this type of design would be highly conducive for integration with an ES2 system, followed by ES3, ES1, and finally ES4 through ES6. Integration and optimization of this reactor design with an ES2 system should be further investigated or optimized for designs. 
Table 3.3-4. SFR plant overview

\begin{tabular}{lccccc}
\hline Abbreviation & $\begin{array}{c}\text { Reactor } \\
\text { thermal } \\
\text { output } \\
\text { [MWth] }\end{array}$ & $\begin{array}{c}\text { Power plant } \\
\text { output, gross } \\
\text { [MWe] }\end{array}$ & $\begin{array}{c}\text { Power plant } \\
\text { output, net } \\
\text { [Mwe] }\end{array}$ & $\begin{array}{c}\text { Plant } \\
\text { efficiency, net } \\
\text { [\%] }\end{array}$ & $\begin{array}{c}\text { Non-electrical } \\
\text { applications }\end{array}$ \\
\hline $4 S$ & 30 & 10 & 10 & 33.3 & Multiple \\
AFR-100 & 250 & - & 100 & 41 & - \\
ARC-100 & 260 & - & 100 & 40 & - \\
ASTRID & 1500 & 600 & 600 & - & - \\
BN-1200 & 2800 & 1220 & 1140 & 40.7 & - \\
CFR-600 & 1500 & 600 & 600 & 40 & - \\
FBR-1 \& 2 & 1250 & 500 & 500 & 41.7 & - \\
JSFR & 3530 & 750 & 750 & - & - \\
MBIR & 150 & 60 & 60 & - & - \\
PGSFR & 150 & - & - & - & - \\
PRISM & 840 & 311 & 311 & - & - \\
TWR-P & 1475 & 600 & 600 & - & - \\
\hline
\end{tabular}

Items in italics are considered SMRs; listed values are for the minimum reactor amount only.

This type of reactor could meet the needs of IPs 12-16 with minimal topping off heat. Higher heat industrial processes will need additional fuel sources to bring their processes to the correct temperatures if they use this type of power plant for industrial process heat. In addition to the lower temperatures, the scale of most of these plant designs may be difficult to integrate into current industrial sites since their designs tend toward larger baseload power to achieve higher economies of scale often attributed to larger reactors. Due to the reactor size, it may be necessary to transport heat over a greater distance, leading to larger capital costs and heat losses.

\subsection{LEAD-COOLED FAST REACTORS}

Lead-cooled fast reactors use a pool type primary loop design with molten lead or a molten lead eutectic coolant heat transfer medium. These plant designs are considered to be at the lowest TRL, with several gaps within the necessary knowledge and testing base. Because of their low TRL of $\sim 3$ [8], most leadcooled fast reactor designs described in the ARIS database are experimental or demonstration reactors; only a few of these designs are specified for commercial use. However, due to this plant type's inherent safety and ability to burn actinides such as thorium, MOX fuel, and spent fuel, lead-cooled fast reactors have garnered significant interest for further development, and many experimental reactors are planned. Once testing data and feasibility studies are conducted with a working prototype, designs could accelerate based on the resulting data. The negative aspects of this type of plant are the medium's potential to plate out or solidify, as in the case of lead, as well as the expense for creating a molten lead eutectic cooling medium in order to significantly lower the freezing point. 
Table 3.4-1. Lead-cooled fast reactors

\begin{tabular}{|c|c|c|c|c|c|c|c|}
\hline Abbreviation & Full name & Design org. & Coolant & Moderator & Design status & Country & Purpose \\
\hline ADTC & $\begin{array}{c}\text { Accelerator Driven Thorium } \\
\text { Cycle Reactor }\end{array}$ & $\begin{array}{l}\text { Texas A\&M/Natura } \\
\text { Resources, LLC }\end{array}$ & Lead & No Moderator & $\begin{array}{l}\text { Conceptual } \\
\text { Design }\end{array}$ & USA & Experimental \\
\hline ALFRED & $\begin{array}{l}\text { Advanced Lead Fast Reactor } \\
\text { European Demonstrator }\end{array}$ & Ansaldo Nucleare & Lead & No Moderator & Under Design & $E U$ & Demonstration \\
\hline BREST-OD-300 & BREST-OD-300 & RDIPE & Lead & No Moderator & Under Design & Russia & Demonstration \\
\hline CLEAR-I & $\begin{array}{c}\text { China LEAd-based Research } \\
\text { Reactor }\end{array}$ & $\begin{array}{l}\text { Institute of Nuclear } \\
\text { Energy Safety } \\
\text { Technology }\end{array}$ & $\begin{array}{l}\text { Lead Bismuth } \\
\text { Eutectic alloy }\end{array}$ & No Moderator & $\begin{array}{l}\text { Conceptual } \\
\text { Design }\end{array}$ & China & Experimental \\
\hline ELECTRA & $\begin{array}{c}\text { European Lead Cooled Training } \\
\text { Reactor }\end{array}$ & KTH & Lead & No Moderator & Under Design & Sweden & Experimental \\
\hline ELFR & European Lead Fast Reactor & Ansaldo Nucleare & Lead & No Moderator & $\begin{array}{l}\text { Conceptual } \\
\text { Design }\end{array}$ & EU & Demonstration \\
\hline ENHS & $\begin{array}{l}\text { Encapsulated Nuclear Heat } \\
\text { Source }\end{array}$ & UC Berkley & $\begin{array}{l}\text { Lead or Lead- } \\
\quad \text { Bismuth }\end{array}$ & No Moderator & $\begin{array}{l}\text { Conceptual } \\
\text { Design }\end{array}$ & $U S A$ & Commercial \\
\hline$G 4 M$ & Gen4 Module & Gen4 Energy Inc. & $\begin{array}{l}\text { Lead Bismuth } \\
\text { Eutectic alloy }\end{array}$ & No Moderator & Under Design & $U S A$ & Commercial \\
\hline LC-E-SSTAR & Lakechime Evolutionary STAR & Lakechime & Lead & No Moderator & $\begin{array}{l}\text { Conceptual } \\
\text { Design }\end{array}$ & Canada & Commercial \\
\hline$L F R-A S-200$ & $\begin{array}{l}\text { Lead-cooled Fast Reactor } \\
\text { Amphora-Shaped } 200\end{array}$ & Hydromine Energy S.a.r.l & Lead & No moderator & $\begin{array}{l}\text { Conceptual } \\
\text { Design }\end{array}$ & Luxembourg & Commercial \\
\hline MYRRHA & $\begin{array}{c}\text { Multi-purpose Hybrid Research } \\
\text { Reactor for High-tech } \\
\text { Applications }\end{array}$ & $\begin{array}{c}\text { Belgian Nuclear } \\
\text { Research Centre } \\
(S C K \bullet C E N)\end{array}$ & $\begin{array}{l}\text { Lead Bismuth } \\
\text { Eutectic alloy }\end{array}$ & No Moderator & Under Design & Belgium & Experimental \\
\hline PEACER & $\begin{array}{l}\text { Proliferation-resistant } \\
\text { Environment-friendly Accident- } \\
\text { tolerant Continuable and } \\
\text { Economical Reactor }\end{array}$ & $\begin{array}{l}\text { Seoul National } \\
\text { University }\end{array}$ & $\begin{array}{l}\text { Lead Bismuth } \\
\text { Eutectic alloy }\end{array}$ & No Moderator & $\begin{array}{l}\text { Conceptual } \\
\text { Design }\end{array}$ & Rep. of Korea & Demonstration \\
\hline SEALER & Swedish Advanced Lead Reactor & LeadCold & Lead & No Moderator & $\begin{array}{l}\text { Conceptual } \\
\text { Design }\end{array}$ & Sweden & Commercial \\
\hline SSTAR & $\begin{array}{l}\text { Secure Transportable } \\
\text { Autonomous Reactor }\end{array}$ & $\begin{array}{l}\text { Argonne National } \\
\text { Laboratory }\end{array}$ & Lead & No Moderator & $\begin{array}{l}\text { Conceptual } \\
\text { Design }\end{array}$ & USA & Commercial \\
\hline STAR-LM & $\begin{array}{l}\text { Secure Transportable } \\
\text { Autonomous Reactor }\end{array}$ & $\begin{array}{l}\text { Argonne National } \\
\text { Laboratory }\end{array}$ & Lead & No Moderator & $\begin{array}{l}\text { Conceptual } \\
\text { Design }\end{array}$ & USA & Commercial \\
\hline$S V B R-100$ & SVBR-100 & AKME Engineering & $\begin{array}{l}\text { Lead Bismuth } \\
\text { Eutectic alloy }\end{array}$ & No Moderator & Under Design & Russia & Commercial \\
\hline W-LFR & $\begin{array}{l}\text { Westinghouse Lead-cooled Fast } \\
\text { Reactor }\end{array}$ & $\begin{array}{l}\text { Westinghouse Electric } \\
\text { Company LLC }\end{array}$ & Lead & No Moderator & $\begin{array}{l}\text { Conceptual } \\
\text { Design }\end{array}$ & USA & Demonstration \\
\hline
\end{tabular}

Items in italics are considered SMRs; listed values are for the minimum reactor amount only. 


\subsubsection{Lead-Cooled Primary Loop System Characterization}

Lead-cooled reactor concepts are fast reactors that can use either a liquid lead or a lead bismuth eutectic alloy as the cooling medium. Most designs found during this literature review are the pool type similar to sodium-cooled fast reactors. Primary coolant output temperatures range from 400 to $650^{\circ} \mathrm{C}$, along with net efficiencies approaching or exceeding $40 \%$. Fuel within the reactor core is contained within fuel pins oriented in a hexagonal fuel assembly of different designs, focusing on trans-uranium actinides for fuel, along with the ability to burn MOX fuel in most designs.

Table 3.4-2, Lead-cooled reactor primary system parameter summary

\begin{tabular}{lcccccc}
\hline Abbreviation & $\begin{array}{c}\text { Primary } \\
\text { coolant flow } \\
\text { rate } \\
{[\mathbf{k g} / \mathbf{s}]}\end{array}$ & $\begin{array}{c}\text { Reactor } \\
\text { operating } \\
\text { pressure } \\
{[\mathbf{M P a}]}\end{array}$ & $\begin{array}{c}\text { Coolant inlet } \\
\text { temperature } \\
{\left[{ }^{\circ} \mathbf{C}\right]}\end{array}$ & $\begin{array}{c}\text { Coolant outlet } \\
\text { temperature } \\
{\left[{ }^{\circ} \mathbf{C}\right]}\end{array}$ & $\begin{array}{c}\text { Delta } \\
\text { temperature } \\
{\left[{ }^{\circ} \mathbf{C}\right]}\end{array}$ & $\begin{array}{c}\text { Reactor } \\
\text { thermal } \\
\text { output } \\
\text { [MWth] }\end{array}$ \\
\hline ADTC & - & - & - & - & - & - \\
ALFRED & - & 0.1 & 400 & 480 & 80 & 300 \\
BREST-OD-300 & - & 0.02 & 420 & 540 & 120 & 700 \\
CLEAR-I & - & 0.05 & 260 & 390 & 130 & 10 \\
ELECTRA & - & - & 400 & 500 & 100 & 0.5 \\
ELFR & - & 0.1 & 400 & 480 & 80 & 1500 \\
ENHS & - & - & - & - & - & - \\
G4M & - & - & - & 500 & 500 & 70 \\
LC-E-SSTAR & - & - & - & - & - & - \\
LFR-AS-200 & 29300 & 0.01 & 420 & 530 & 110 & 480 \\
MYRRHA & - & - & 270 & 410 & 140 & 100 \\
PEACER & - & 0.1 & 300 & 400 & 100 & 850 \\
SEALER & 7400 & 0.1 & 420 & 550 & 130 & 140 \\
SSTAR & - & - & 420 & 564 & - & 45 \\
STAR-LM & - & - & - & - & - & 181 \\
SVBR-100 & - & 6.7 & - & 490 & 490 & 280 \\
W-LFR & 25300 & 0.1 & 390 & 650 & 260 & 950 \\
\hline Items in italics are considered SMRs: listed values are for the minimum reactor amount only & & & \\
\end{tabular}

\subsubsection{Lead-Cooled Secondary Loop System Characterization}

Lead-cooled secondary systems are overwhelmingly water based with a Rankine power cycle. Secondary systems are proposed to have 2 or more loops with multiple once-through steam generators producing steam temperatures from 450 to $530^{\circ} \mathrm{C}$ for proposed power operation plants. Many proposed designs are intended for research reactors at this time. This approach helps to raise the TRL of this particular type of reactor design, but several proposed designs are intended primarily for producing power; their literature does not mention of secondary storage or industrial applications. The W-LFR lists a "Brankine" condensing $\mathrm{S}_{-} \mathrm{CO}_{2}$ secondary concept; however, since the TRL of a S-CO 2 loop is currently low, other systems are being developed in parallel. 
Table 3.4-3. Lead-cooled reactor secondary system parameter summary

\begin{tabular}{lccccc}
\hline Abbreviation & $\begin{array}{c}\text { Steam flow } \\
\text { rate } \\
{[\mathbf{k g} / \mathbf{s}]}\end{array}$ & $\begin{array}{c}\text { Steam } \\
\text { pressure } \\
{[\mathbf{M P a}]}\end{array}$ & $\begin{array}{c}\text { Steam } \\
\text { temperature } \\
{\left[{ }^{\circ} \mathbf{C}\right]}\end{array}$ & $\begin{array}{c}\text { Feedwater flow } \\
\text { rate } \\
{[\mathbf{k g} / \mathbf{s}]}\end{array}$ & $\begin{array}{c}\text { Feedwater } \\
\text { temperature } \\
{\left[{ }^{\circ} \mathbf{C}\right]}\end{array}$ \\
\hline ADTC & - & - & - & - & - \\
ALFRED & - & - & - & - & - \\
BREST-OD-300 & - & - & - & - & - \\
CLEAR-I & - & 4 & 230 & - & 215 \\
ELECTRA & - & - & - & - & - \\
ELFR & - & 18 & 450 & - & - \\
ENHS & - & - & - & - & - \\
G4M & - & - & - & - & - \\
LC-E-SSTAR & - & - & - & - & - \\
LFR-AS-200 & 282 & 18 & 500 & 282 & 340 \\
MYRRHA & - & - & - & - & - \\
PEACER & - & - & - & - & - \\
SEALER & 76 & 15 & 530 & - & 335 \\
SSTAR & 245 & 20 & $550 / 31.25$ & - & - \\
STAR-LM & - & - & - & - & - \\
SVBR-100 & - & - & - & - & - \\
W-LFR & - & - & - & - & - \\
\hline
\end{tabular}

Items in italics are considered SMRs; listed values are for the minimum reactor amount only.

Lead-cooled fast reactors have many of the same characteristics as the sodium fast-cooled reactors and molten salt reactors, in that they often have similar power outputs and secondary power production parameters. Thus, the conclusion for matching industrial processes remains the same.

\subsubsection{Lead-Cooled Reactor Summary}

The reactor designs listed in the ARIS database specify base load as their primary purpose, with few mentions of being a part of an IES. The high temperatures produced by this type of reactor show promise for both production of secondary steam other industrial processes, as well as thermal storage. The W-LFR states in the design description that the plant was designed to load follow with the secondary system to allow for 65 to $125 \%$ of normal operating power levels, thus utilizing thermal energy storage. Also, the LFR-AS-200 indicates a secondary system power from 20 to $110 \%$, with a hot water storage tank for additional energy storage and temporary operation up to the $110 \%$ capacity. 
Table 3.4-4. Lead-cooled reactor overview

\begin{tabular}{lccccc}
\hline Abbreviation & $\begin{array}{c}\text { Reactor } \\
\text { thermal output } \\
\text { [MWth] }\end{array}$ & $\begin{array}{c}\text { Power plant } \\
\text { output, gross } \\
\text { [MWe] }\end{array}$ & $\begin{array}{c}\text { Power plant } \\
\text { output, net } \\
\text { [Mwe] }\end{array}$ & $\begin{array}{c}\text { Plant } \\
\text { efficiency, net } \\
\text { [\%] }\end{array}$ & $\begin{array}{c}\text { Non-electrical } \\
\text { applications }\end{array}$ \\
\hline ADTC & - & - & - & - & - \\
ALFRED & 300 & 125 & 125 & - & - \\
BREST-OD-300 & 700 & 300 & 300 & - & - \\
CLEAR-I & 10 & - & - & - & - \\
ELECTRA & 0.5 & - & - & - & - \\
ELFR & 1500 & 630 & 630 & 40 & - \\
ENHS & & - & - & - & - \\
G4M & 70 & 25 & 25 & - & - \\
LC-E-SSTAR & - & - & - & - & Heat for industrial \\
LFR-AS-200 & 480 & 212 & 200 & 42 & processes \\
MYRRHA & 100 & - & - & - & - \\
PEACER & 850 & 300 & 300 & - & - \\
SEALER & 140 & 58 & 55 & 39.3 & Desalinization \\
SSTAR & 45 & - & - & 44.2 & Desalinization \\
STAR-LM & 181 & - & - & - & - \\
SVBR-100 & 280 & 101 & 101 & - & - \\
W-LFR & 950 & 468 & 460 & 48.4 & \\
\hline
\end{tabular}

Items in italics are considered SMRs; listed values are for the minimum reactor amount only.

As detailed here, lead-cooled fast reactors are designed to have much lower thermal output while maintaining a higher efficiency than the current LWR fleet. Also, the designs listed account for the use of thermal heat or other non-electrical applications within their designs. Still, power production remains the primary focus for most reactors. Due to this focus and the relatively low TRL of this reactor type, leadcooled fast reactors could be a primary target to optimize with energy storage.

Energy storage for this reactor type would be similar to that included in current LWRs. The presence of a secondary power production steam cycle means that any of the secondary storage options that can utilize the steam directly would be prime options, followed by other forms. The primary concepts that could be coupled would be ES-1 and ES-4 for their efficient use of the secondary steam, followed closely by ES-3 and ES-2.

For certain high-temperature processes, IPs 1-8 could utilize the steam temperatures produced by the power production cycle, but they would still need additional sources of energy to reach the temperatures needed for even the lower levels of the high process heat. The lower levels of industrial processes are easily obtainable, so industrial processes IP12-IP16 could easily use process heat at temperature levels produced by lead-cooled reactors.

The majority of the designs reviewed do not consider secondary processes other than base load power production or research, so the applicability of this reactor type to an IES should be an active area of study. 


\subsection{MOLTEN SALT REACTORS}

Molten salt reactor design is very similar to sodium cooled fast reactor designs, sharing advantages and disadvantages, as well as TRLs. However, based on the completion of the Molten Salt Reactor Experiment (MSRE) at Oak Ridge National Laboratory (ORNL), the technical feasibility of this type of plant has been proven beyond that of other advanced reactor types, and many designs credit the MSRE. Even though data exist for this type of reactor, the TRL remains fairly low $(\sim 3)$ for this type of reactor, as well [8]. Graphite is the common moderator used in these types of reactors, although the form of the graphite depends on the fuel design. 
Table 3.5-1. Molten salt reactors

\begin{tabular}{|c|c|c|c|c|c|c|c|}
\hline Abbreviation & Full name & Design Org. & Coolant & Moderator & Design Status & Country & Purpose \\
\hline Elysium & Elysium Molten Salt Reactor & Elysium & Molten Salt & No Moderator & Under Design & Canada & Commercial \\
\hline FHR & $\begin{array}{l}\text { Fluoride-Salt Cooled High } \\
\text { Temperature Reactor }\end{array}$ & $M I T \& U C B$ & Fluoride Salts & No Moderator & Conceptual Design & $U S A$ & Experimental \\
\hline Gem*STAR/MuSTAR & $\begin{array}{l}\text { Green Energy Multiplier- } \\
\text { Subcritical Technology for } \\
\text { Advanced Reactors }\end{array}$ & Virginia Tech/Muons Inc & Molten Salt & Graphite & Conceptual Design & $U S A$ & Demonstration \\
\hline$I M S R-400$ & Integral Molten Salt Reactor-400 & Terrestrial Energy & Fluoride Salts & Graphite & Under Design & Canada & Commercial \\
\hline LFTR & Liquid Fluoride Thorium Reactor & FLiBe Energy & Fluoride Salts & Graphite & Conceptual Design & $U S A$ & Commercial \\
\hline$L S F R$ & Liquid Salt Fast Reactor & $M I T$ & Chloride Salt & No Moderator & Conceptual Design & $U S A$ & Demonstration \\
\hline$M C F R$ & $\begin{array}{c}\text { Molten Chloride Salt Fast } \\
\text { Reactor }\end{array}$ & TerraPower & Molten Salt & No Moderator & Under Design & $U S A$ & Commercial \\
\hline$M k 1 P B-F H R$ & $\begin{array}{c}\text { Mark } 1 \text { Pebble-Bed Fluoride-Salt- } \\
\text { Cooled High Temperature } \\
\text { Reactor }\end{array}$ & $\begin{array}{c}\text { University of California, } \\
\text { Berkeley }\end{array}$ & Fluoride Salts & Graphite & Under Design & $U S A$ & Commercial \\
\hline MSFR & Molten Salt Fast Reactors & CNRS & Molten Salt & No Moderator & Conceptual Design & France & Demonstration \\
\hline$M S R-F U J I$ & Molten Salt Reactor-FUJI & $\begin{array}{c}\text { International Thorium } \\
\text { Molten-Salt Forum: ITMSF }\end{array}$ & Fluoride Salts & Graphite & Conceptual Design & Japan & Commercial \\
\hline MSTW & Molten Salt Thermal Wasteburner & Seaborg Technologies & Molten Salt & Graphite & Conceptual Design & Denmark & Commercial \\
\hline SmAHTR & $\begin{array}{c}\text { Small fluoride salt-cooled High } \\
\text { Temperature Reactor }\end{array}$ & $\begin{array}{l}\text { Oak Ridge National } \\
\text { Laboratory }\end{array}$ & Fluoride Salts & Graphite & Under Design & $U S A$ & Demonstration \\
\hline SSR & Stable Molten Salt Reactor & Moltex Energy & - & - & Conceptual Design & USA & Commercial \\
\hline TAP & Transatomic Power Reactor & Transatomic & Fluoride Salt & $\begin{array}{l}\text { Zirconium } \\
\text { Hydride }\end{array}$ & - & - & Commercial \\
\hline ThorCon & ThorCon & ThorCon US, Inc. & Molten Salt & Graphite & Detailed Design & USA & Commercial \\
\hline Thorenco & - & Thorenco & Fluoride Salt & - & Conceptual Design & - & Commercial \\
\hline
\end{tabular}

Items in italics are considered SMRs; listed values are for the minimum reactor amount only. 


\subsubsection{MSR Primary Loop System Characterization}

The dominant designs for an MSR's primary reactor loop are a forced convection loop with MOX fuel actinides or thorium mixed together and then melted. The dominant salt media selected for the primary loop are fluoride salts, but this could change based on data and future experiments. For reactors using a thermal spectrum, fuel channels moderated by graphite cause the nuclear reactor to go critical while the fluid is held within the channels, or in the case of the MK1 PB-FHR, a TRISO fuel particle. However, the primary distinguishing feature of the MSR design concept is that the fuel is molten within the heat transfer medium of the primary loop. As in LFRs, the pressures for MSRs are typically near atmospheric pressure in the primary loop. An intermediary loop is often used to achieve primarily radioactivity isolation, in concert with a medium that is not reactive with water, before transferring through another heat exchanger to the power production cycle. All the MSR designs reflect high coolant output temperatures from 650 to $750^{\circ} \mathrm{C}$. In order to isolate the molten fuel contained within the primary reactor loop medium, these reactors have an intermediate loop that is often made of another molten salt, or in some cases, it is the similar salt as that in the primary loop, without the fuel within the coolant. While this adds additional expense and complexity to a plant, it also adds an additional system that could be used to redirect heat to an IES without significant design changes.

Table 3.5-2. Molten salt reactor primary system parameter summary

\begin{tabular}{lcccccc}
\hline Abbreviation & $\begin{array}{c}\text { Primary } \\
\text { coolant } \\
\text { flow rate } \\
{[\mathbf{k g} / \mathbf{s}]}\end{array}$ & $\begin{array}{c}\text { Reactor } \\
\text { operating } \\
\text { pressure } \\
{[\mathbf{M P a}]}\end{array}$ & $\begin{array}{c}\text { Coolant } \\
\text { inlet } \\
\text { temperature } \\
{\left[{ }^{\circ} \mathbf{C}\right]}\end{array}$ & $\begin{array}{c}\text { Coolant } \\
\text { outlet } \\
\text { temperature } \\
{\left[{ }^{\circ} \mathbf{C}\right]}\end{array}$ & $\begin{array}{c}\text { Delta } \\
\text { temperature } \\
{\left[{ }^{\circ} \mathbf{C}\right]}\end{array}$ & $\begin{array}{c}\text { Reactor } \\
\text { thermal } \\
\text { output } \\
{[\mathbf{M W t h}]}\end{array}$ \\
\hline Elysium & - & - & - & - & - & 2700 \\
FHR & - & - & - & - & - & - \\
Gem ${ }^{*}$ STAR/MuSTAR & - & - & 550 & 650 & 100 & 500 \\
IMSR-400 & 5400 & 0.4 & 625 & 670 & 75 & 400 \\
LFTR & - & 0.1 & 500 & 650 & 150 & 600 \\
LSFR & - & - & 496 & - & - & 600 \\
MCFR & - & - & - & - & - & - \\
Mk1 PB-FHR & 976 & 0.3 & 600 & 700 & 100 & 236 \\
MSFR & - & 1 & 650 & 750 & 100 & 3000 \\
MSR-FUJI & 2400 & 0.5 & 565 & 704 & 139 & 450 \\
MSTW & - & 0.1 & 600 & 700 & 100 & 270 \\
SmAHTR & - & 1 & 670 & 700 & 30 & 125 \\
SSR & - & - & - & - & - & - \\
TAP & - & 0.1 & - & 650 & - & 1250 \\
ThorCon & 2934 & 0.39 & 565 & 704 & 139 & 557 \\
Thorenco & - & - & - & - & - & 50 \\
\hline
\end{tabular}

Items in italics are considered SMRs; listed values are for the minimum reactor amount only. 


\subsubsection{MSR Power Production Loop System Characterization}

MSR designs typically differ from other designs in that there is a loop of molten salt between the power production cycle and the fuel molten salt primary loop; this is similar to sodium-cooled reactor design. The pressure difference between the primary and secondary loops is such that leaks in the salt-salt heat exchanger would result in flow from the secondary loop to the primary loop, thus preventing release of fuel salt into the secondary loop. Finally, the power production loops for these facilities include Brayton and Rankine cycles, with secondary temperatures ranging from 530 to $585^{\circ} \mathrm{C}$ and with a target plant net efficiency rating from 42 to $47 \%$. The standard water Rankine cycle is the preferred power production cycle; however, the LFTR does have a Brayton $\mathrm{S}-\mathrm{CO}_{2}$ loop for the power production cycle.

Table 3.5-3. Molten salt reactor secondary system parameter summary

\begin{tabular}{lccccc}
\hline Abbreviation & $\begin{array}{c}\text { Steam flow } \\
\text { rate } \\
{[\mathbf{k g} / \mathbf{s}]}\end{array}$ & $\begin{array}{c}\text { Steam } \\
\text { pressure } \\
{[\mathbf{M P a}]}\end{array}$ & $\begin{array}{c}\text { Steam } \\
\text { temperature } \\
{\left[{ }^{\circ} \mathbf{C}\right]}\end{array}$ & $\begin{array}{c}\text { Feedwater flow } \\
\text { rate } \\
{[\mathbf{k g} / \mathbf{s}]}\end{array}$ & $\begin{array}{c}\text { Feedwater } \\
\text { temperature } \\
{\left[{ }^{\circ} \mathbf{C}\right]}\end{array}$ \\
\hline Elysium & - & - & - & - & - \\
FHR & - & - & - & - & - \\
Gem ${ }^{2}$ STAR/MuSTAR & - & - & - & - & - \\
IMSR-400 & 148.5 & 19 & 585 & 148.5 & 240 \\
LFTR & - & - & - & - & - \\
LSFR & 3190 & 20 & 530 & - & - \\
MCFR & - & - & - & - & - \\
Mk1 PB-FHR & - & - & - & - & - \\
MSFR & - & - & - & - & - \\
MSR-FUJI & 252 & - & 538 & - & - \\
MSTW & - & - & 550 & - & - \\
SmAHTR & - & - & - & - & - \\
SSR & - & - & - & - & - \\
TAP & - & - & - & - & - \\
ThorCon & 425.4 & 25.5 & 547 & - & 288 \\
Thorenco & - & - & - & - & - \\
\hline
\end{tabular}

Items in italics are considered SMRs; listed values are for the minimum reactor amount only. 


\subsubsection{MSR Summary}

Table 3.5-4. MSR Plant Overview

\begin{tabular}{lccccc}
\hline Abbreviation & $\begin{array}{c}\text { Reactor } \\
\text { thermal output } \\
\text { [MWth] }\end{array}$ & $\begin{array}{c}\text { Power plant } \\
\text { output, gross } \\
\text { [Mwe] }\end{array}$ & $\begin{array}{c}\text { Power plant } \\
\text { output, net } \\
\text { [Mwe] }\end{array}$ & $\begin{array}{c}\text { Plant efficiency, } \\
\text { net } \\
{[\%]}\end{array}$ & $\begin{array}{c}\text { Non-electrical } \\
\text { applications }\end{array}$ \\
\hline Elysium & 2700 & - & - & - & - \\
FHR & - & - & - & - & - \\
Gem *STAR/MuSTA & 500 & - & - & - & - \\
$R$ & 400 & 194 & 185 & 46 & Multiple \\
IMSR-400 & 600 & 250 & - & 45 & - \\
LFTR & 600 & 389 & 266 & 44 & - \\
LSFR & & - & - & - & - \\
MCFR & 236 & 100 & - & 42.5 & - \\
Mk1 PB-FHR & 3000 & 1500 & 1500 & - & - \\
MSFR & 450 & 207 & 200 & 44.4 & Multiple \\
MSR-FUJI & 270 & 115 & - & 42.5 & Multiple \\
MSTW & 125 & - & - & - & H2 production \\
SmAHTR & - & - & - & - & - \\
SSR & 1250 & 550 & 520 & 44 & - \\
TAP & 557 & 258 & 250 & 46.4 & - \\
ThorCon & - & - & - & - & - \\
Thorenco & & & & & \\
\hline
\end{tabular}

Items in italics are considered SMRs; listed values are for the minimum reactor amount only.

Currently, MSR design literature mentions having multiple non-electrical capabilities more times than other designs within their stated goals, making this category a prime target to be studied for IES applications. Secondary sides are also consistent with current technologies producing power in LWRs, so they are based on proven systems, with improvements rather than novel concepts that require additional research. An exception to these generalities is shown in the plants using a $\mathrm{S}-\mathrm{CO}_{2}$ Brayton cycle for power conversion, which would have a lower TRL associated with such a system. As discussed above, an intermediary loop is often necessary to contain the molten fuel in the primary loop and to limit reactions with water or other systems, but it also adds cost and complexity to the plant. When this loop is considered from the perspective of an IES, however, the option for this secondary loop provides capabilities to provide heat energy to secondary processes prior to a power conversion loop. ES-2 systems could easily operate with an intermediary loop similar to that described for SFRs. By simply adding additional fluid inventory to this loop and syphoning out the heated intermediate fluid to storage for use at a later time, the reactor could maintain a high-capacity factor at or near $100 \%$ while only generating a minimum amount of power in the turbine to facilitate a quick return to $100 \%$ energy production or greater. This type of plant can also integrate with ES-1, ES-3, and ES-4 systems, as well, by using the steam power production loop.

MSR primary coolant temperatures maintain some of the highest temperatures of the designs summarized in this report, with secondary temperatures second only to the gas-cooled reactor types. Longer distances may present corrosion or plate out issues for the intermediate loops in these reactor types, which in turn could lead to additional expense and restrictions on distance from an industrial process. These concerns could also eliminate certain locations or designs, so coupling with an industrial process may require the 
addition of a steam loop. The high steam temperature can provide enough industrial process heat for IPs 1-8 vs. other reactor designs; however, the lower industrial process temperatures for IP9-IP16 are more easily obtainable without design changes.

Because the MSR concept represents a key area of current research, and due to the design focus on nonenergy production uses for heat, the MSR concept is a key reactor type that can be optimized to use IES concepts. Based on the conclusions outlined above, the MSR concepts under design could be optimized for energy storage to provide economic benefits for the plant. The use of a molten salt fluid medium could limit the ability for the plant to provide primary side process heat and thus rely on the power production loop steam for process heat, which is typically lower than gas-cooled designs.

\section{SUMMARY}

The literature review of the IAEA ARIS database [1] and the Third Way [3] advanced reactor survey, combined with review of additional relevant materials, has led to selection of 61 advanced reactors of various types with various degrees of design for review.

The distribution of these reactors is shown in Figure 3.5-1.
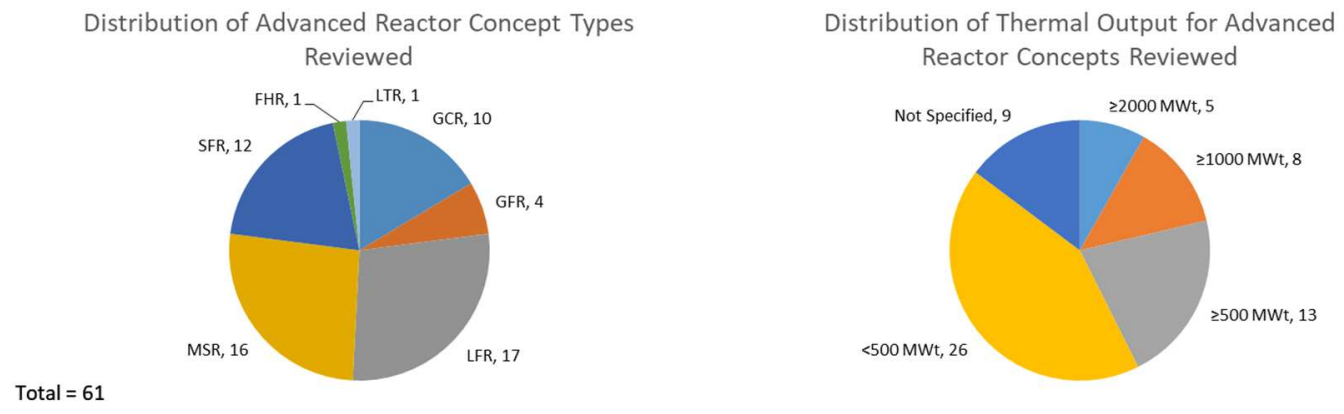

Distribution of Electrical Output for Advanced

Reactor Concepts Reviewed

Distribuion of Net Efficiencies for Advanced

Reactor Concepts Reviewed
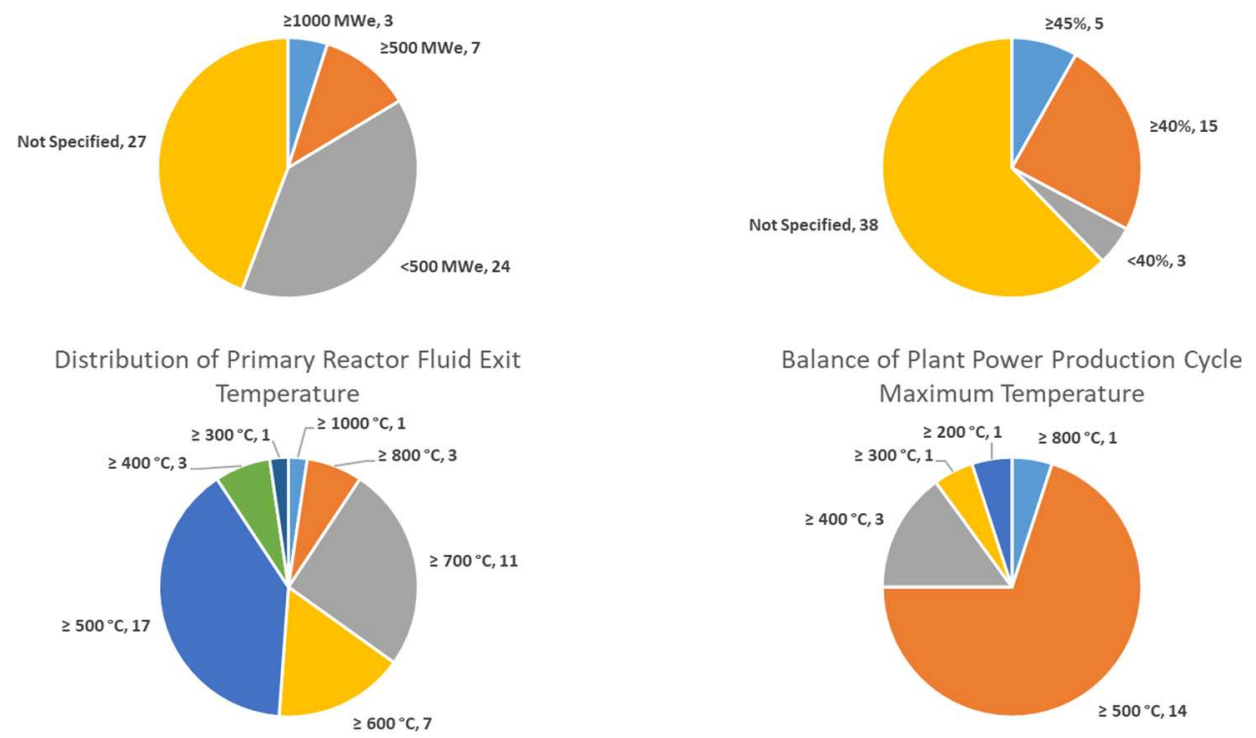

Figure 3.5-1. Breakdown of Reviewed Reactor Types. 
Current LWR/BWR power plants maintain greater than 2,000 MWt, and they often maintain at least two reactors on site to allow for greater economic efficiency through economies of scale. However, as evidenced in the diagrams presented above, the advanced reactor concepts have trended toward smaller MWt and MWe concepts with higher efficiency ratings. This is because many reactor designs allow for a modular approach in which more than one reactor can be placed on site to scale up the production of thermal energy for power or other processes. Additionally, many designs concepts advertise that they can be scaled up or down in power and size to meet a customer's need, so they can take a reactor to higher or lower thermal power simply by changing the design in some way. This flexibility can help with siting these plants in current or future industrial settings in rural area or heavily populated areas.

\subsection{ENERGY STORAGE SUMMARY}

The primary designs suited for energy storage concepts are MSRs and SFRs. An intermediate loop can be included for use as a primary storage system to improve the economics of the plant. For these plants, valves could be opened to provide additional intermediate loop fluid while extracting the heated fluid to a sensible storage concept (ES-2). Other concepts such as ES1-ES6 are similar for all plants, depending on whether they transfer energy to a secondary steam or an $\mathrm{S}-\mathrm{CO}_{2}$ loop.

GCR and GFR concepts with a closed Brayton cycle represent a good option for pairing with ES-3 cryogenic systems due to their high-energy efficiency, so coupling with a storage system electronically is a better option than investing in additional heat exchangers to thermally couple the systems.

Sodium and molten salt reactors can provide more bulk energy delivery due to the higher heat capacity of their fluid media. Since the typical SFR and MSR designs include an intermediary heat transfer loop, there is a greater potential for coupling this loop with thermal storage. Therefore, the best storage option for these plants is likely ES-2, sensible heat storage, or ES-4 and ES-5 for heating a high solid heat capacity material.

Lead-cooled fast reactors have a high level of diversity in their core and power production loop parameters, and therefore, they have applications to all types of heat storage options. The high efficiency plants that produce a higher MWt from the reactor core could use any of the energy storage systems listed, and their predominant steam Rankine cycle usage means they could be more conducive to energy storage options using high temperature steam such as options ES-1 and ES-4. However, some plant designs support high energy efficiency similar to that of GCR and GFR designs and thus ES-3 could also be an option for energy storage. Although there is not a clear best option for energy storage coupling, the LFR design can be applied to use any storage option efficiently and therefore could be optimized to work with any storage option reviewed. Further development and testing of the different plant designs along with small and large scale implementation of the various design concepts leads to a better understanding the plant systems and their ability to be coupled with an energy storage system.

\subsection{INDUSTRIAL PROCESS SUMMARY}

Due to the differences in primary fluid media in the different reactor types, the primary comparison points for temperatures that can be passed to an industrial process would be the power production side temperature. While S- $\mathrm{CO}_{2}$ could be used as the working medium of a power production loop for many of the plants investigated here, the table below assumes that steam is providing the process temperatures. Figure 4.2-1 shows the power production loop average temperatures based on plant type compared to the temperature needs for different industrial processes. 


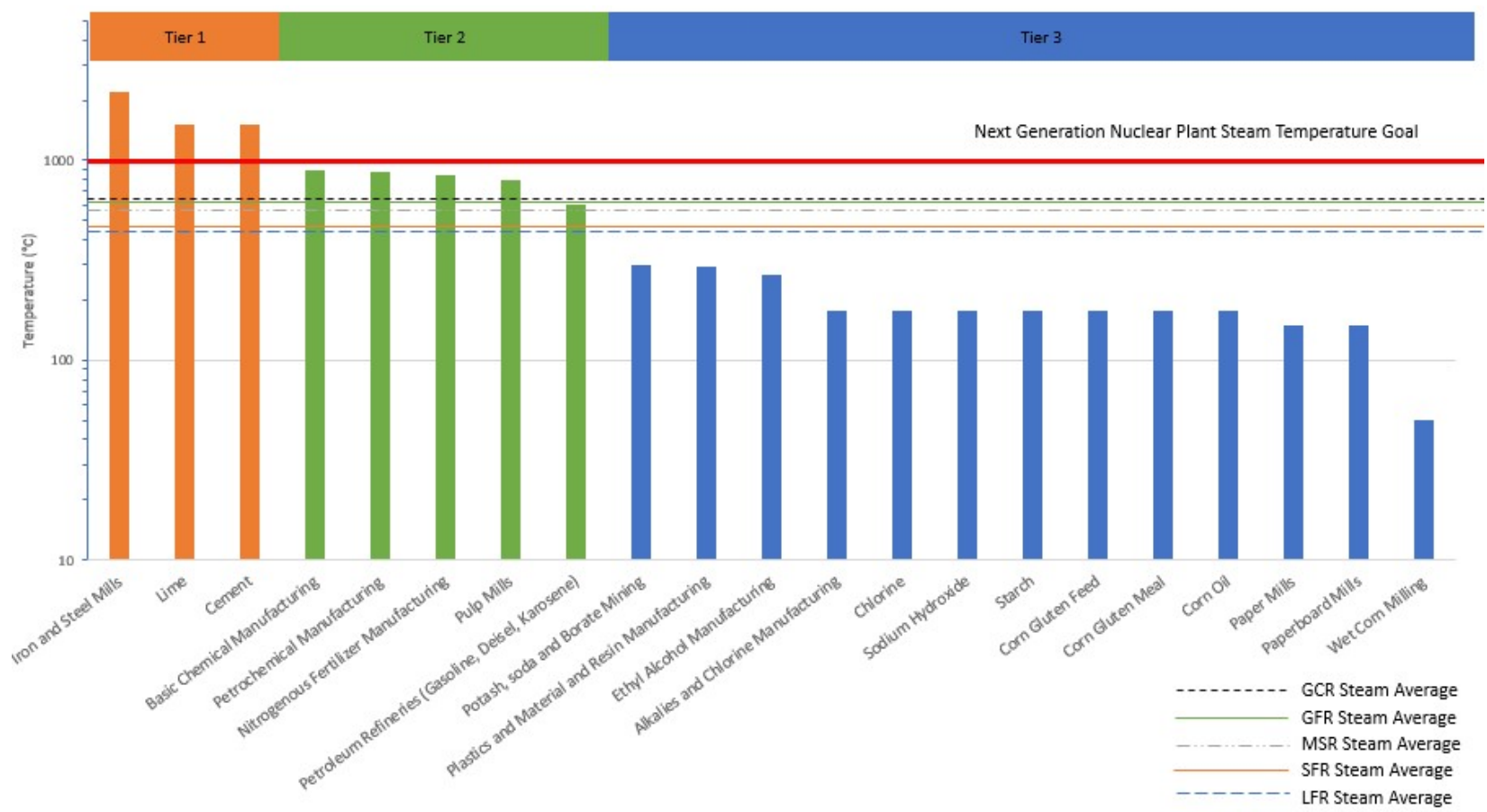

Figure 4.2-1. Industrial process needs vs. average power cycle temperatures $\left({ }^{\circ} \mathrm{C}\right)$ of advanced reactors types.

GCR designs are the most ideal for coupling with industrial processes, but they do not meet the significant temperature requirements for industries such as iron and steel mills, lime and cement. This is expected, since no reactor in the nuclear industry is expected to be able to provide industrial heat or steam on the order of $>1,500^{\circ} \mathrm{C}$. However, GFRs provide the best supply to these industries from a maximum temperature perspective.

For this review GCR, GFR, and MSR technologies meet the criteria for most Tier 2 industrial processes and would significantly reduce the amount of additional top-off heat for Tier 2. At their current TRLs, LFR and SFR designs produce lower temperatures on average and therefore should couple any industrial process heat with Tier 2 and Tier 3 industrial processes.

The breakdown of the industries surveyed based on those reporting as part of the 2019 EPA Greenhouse Gas Reporting Program (GHGRP) [6] and NAICS [10] are shown below. 

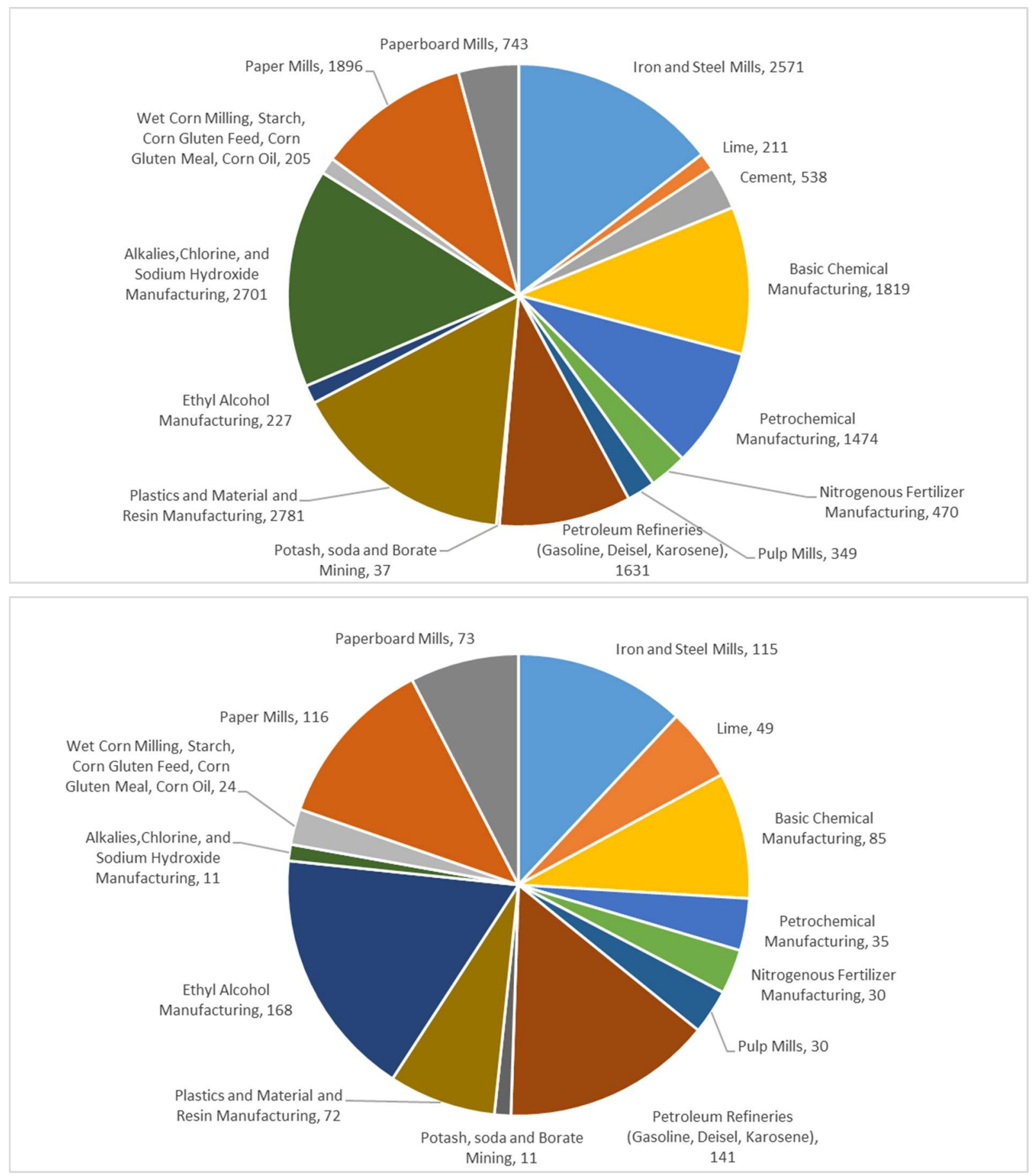

Figure 4.2-2. Industry NAICS plants and GHGRP reporting plants based on industry type.

Production emissions from and average plant of selected industries [6] are summarized in Table 4.2-1 below. 
Table 4.2-1. Target industry heat input consumption summary

\begin{tabular}{|c|c|c|c|c|c|c|}
\hline $\begin{array}{l}\text { Industry } \\
\text { ID }\end{array}$ & Target industry & $\begin{array}{c}\text { Highest process } \\
\text { temperature } \\
\text { using fossil fuels } \\
\left({ }^{\circ} \mathrm{C}\right) \\
\end{array}$ & $\begin{array}{c}\text { Average plant } \\
\text { heat use } \\
\text { (MMBtu/day) }\end{array}$ & $\begin{array}{c}\text { Energy use } \\
\text { for heat } \\
\text { production } \\
\text { (TJ/Day) }\end{array}$ & $\begin{array}{c}\text { Energy use } \\
\text { for heat } \\
\text { production } \\
(\mathrm{MW}) \\
\end{array}$ & $\begin{array}{l}\text { Number of } \\
\text { NAICS } \\
\text { facilities } \\
\text { (2019) }\end{array}$ \\
\hline IP1 & Iron and steel mills & 2,200 & 2,290 & 2.42 & 28.0 & 2,571 \\
\hline IP2 & Lime & 1,500 & 11,800 & 3.05 & 35.3 & 211 \\
\hline IP3 & Cement & 1,500 & 11,800 & 9.40 & 108.8 & 538 \\
\hline IP4 & $\begin{array}{l}\text { Basic chemical } \\
\text { manufacturing }\end{array}$ & 900 & 12,300 & 12.90 & 149.3 & 1,819 \\
\hline IP5 & $\begin{array}{l}\text { Petrochemical } \\
\text { manufacturing }\end{array}$ & 875 & 2,250 & 2.37 & 27.4 & 1,474 \\
\hline IP6 & $\begin{array}{l}\text { Nitrogenous fertilizer } \\
\text { manufacturing }\end{array}$ & 850 & 6,660 & 7.03 & 81.4 & 470 \\
\hline IP7 & Pulp mills & 800 & 4,160 & 6.14 & 71.1 & 349 \\
\hline IP8 & $\begin{array}{l}\text { Petroleum refineries } \\
\text { (gasoline, diesel, } \\
\text { kerosene) }\end{array}$ & 600 & 7,800 & 8.23 & 95.3 & 1,631 \\
\hline IP9 & $\begin{array}{l}\text { Potash, soda and borate } \\
\text { mining }\end{array}$ & 300 & 25,000 & 26.00 & 300.9 & 37 \\
\hline IP10 & $\begin{array}{l}\text { Plastics and material and } \\
\text { resin manufacturing }\end{array}$ & 291 & 10,061 & 10.60 & 122.7 & 2,781 \\
\hline IP11 & $\begin{array}{l}\text { Ethyl alcohol } \\
\text { manufacturing }\end{array}$ & 266 & 1,670 & 1.76 & 20.4 & 227 \\
\hline IP12 & $\begin{array}{l}\text { Alkalis, chlorine, and } \\
\text { sodium hydroxide } \\
\text { manufacturing }\end{array}$ & 177 & 4,040 & 4.26 & 49.3 & 2,701 \\
\hline IP13 & $\begin{array}{l}\text { Starch, corn gluten feed, } \\
\text { corn gluten meal, corn } \\
\text { oil manufacturing }\end{array}$ & 177 & 7,640 & 8.06 & 93.3 & $205^{*}$ \\
\hline IP14 & Paper mills & \multirow{2}{*}{150} & \multirow{2}{*}{20,000} & \multirow{2}{*}{21.10} & \multirow{2}{*}{244.2} & 1,896 \\
\hline IP15 & Paperboard mills & & & & & 743 \\
\hline IP16 & Wet corn milling & 50 & 7,640 & $8.06^{*}$ & $93.3 *$ & $205^{*}$ \\
\hline
\end{tabular}

* Values include all wet corn milling items.

Based on the information presented in McMillan [6] for energy input to maintain process heat, a great deal of lower power nuclear plants $(<200 \mathrm{MWt})$ could provide the necessary energy to match the selected industrial processes; however, efficiency must be considered. Additionally, the process temperatures given are the maximum process temperatures for the given industry, so it may be possible to use remaining energy to produce lower temperatures for other processes at the plant. Based on these considerations, it is assumed that $70 \%$ of a plant's thermal energy is lost to the environment. This assumption for some processes could be conservative, while for others, the transfer of thermal energy may be capable of reaching much higher efficiencies. Table 4.2-2 summarizes details of the plants, showing MWth ratings for the plant and steam temperature. Note that the steam temperature for some plants could be another medium. 
Table 4.2-2. Summary of surveyed advanced reactors for potential applications in process heat co-generation

\begin{tabular}{lccc}
\hline Abbreviation & $\begin{array}{c}\text { Steam } \\
\text { temperature } \\
{\left[{ }^{\circ} \mathbf{C}\right]}\end{array}$ & $\begin{array}{c}\text { Reactor thermal } \\
\text { output } \\
\text { [MWth] }\end{array}$ & $\begin{array}{c}\text { Reactor available } \\
\text { heat (70\%) } \\
{[\mathbf{M W}]}\end{array}$ \\
\hline GT-MHR & 848 & 600 & 420 \\
$I M S R-400$ & 585 & 400 & 280 \\
HTR-PM & 566 & 500 & 350 \\
Xe-100 & 565 & 200 & 140 \\
MSTW & 550 & 270 & 189 \\
SSTAR & 550 & 45 & 32 \\
ThorCon & 547 & 557 & 390 \\
PBMR & 540 & 400 & 280 \\
MSR-FUJI & 538 & 450 & 315 \\
LSFR & 530 & 600 & 420 \\
SEALER & 530 & 140 & 98 \\
AFR-100 & 515 & 250 & 175 \\
BN-1200 & 510 & 2,800 & 1,960 \\
LFR- $A S-200$ & 500 & 480 & 336 \\
$4 S$ & 453 & 30 & 21 \\
ELFR & 450 & 1,500 & 1,050 \\
FBR- 1 \& 2 & 450 & 1,250 & 875 \\
LEADIR-PS100 & 370 & 30 & 21 \\
CLEAR-I & 230 & 10 & 7 \\
\hline
\end{tabular}

Items in italics are considered SMRs.

Because any power plant connected to a facility can generate electrical energy to salvage any excess thermal energy not used for a process, the selection of plants that could be used for each of the industrial processes surveyed is based on (1) providing power levels greater than the thermal needs of the system, and (2) providing a steam temperature higher than the process temperature needed. The final consideration is for reactors that are considered SMRs with the capability of having multiple units. If plants can meet the above criteria with $<8$ units, and preferably with $1-4$ units, then they are included as options. 
Table 4.2-3. Possible Reactors Based on the Target industry Heat and Temperature Requirements

\begin{tabular}{|c|c|c|c|c|c|c|}
\hline Process temperature $\left({ }^{\circ} \mathrm{C}\right)$ & Industry ID & Target industry & $\begin{array}{c}\text { Highest process temperature } \\
\text { using fossil fuels }\left[{ }^{\circ} \mathrm{C}\right]\end{array}$ & $\begin{array}{l}\text { Energy use for heat } \\
\text { production [MW] }\end{array}$ & $\begin{array}{l}\text { Potent } \\
\text { match }\end{array}$ & \\
\hline \multirow{3}{*}{$\begin{array}{l}\text { Tier } 1 \\
2,200-1,500\end{array}$} & IP1 & Iron and steel mills & 2,200 & 28.0 & $\begin{array}{l}G T-M H R \\
\text { HTR-PM }\end{array}$ & $\begin{array}{c}\text { IMSR-400 } \\
X e-100\end{array}$ \\
\hline & IP2 & Lime & 1,500 & 35.3 & $\begin{array}{l}\text { GT-MHR } \\
\text { HTR-PM }\end{array}$ & $\begin{array}{c}I M S R-400 \\
X e-100\end{array}$ \\
\hline & IP3 & Cement & 1,500 & 108.8 & $\begin{array}{l}G T-M H R \\
\text { HTR-PM }\end{array}$ & $\begin{array}{c}I M S R-400 \\
X e-100\end{array}$ \\
\hline \multirow{5}{*}{$\begin{array}{l}\text { Tier } 2 \\
900-600\end{array}$} & IP4 & Basic chemical manufacturing & 900 & 149.3 & $\begin{array}{l}\text { GT-MHR } \\
\text { HTR-PM }\end{array}$ & IMSR-400 \\
\hline & IP5 & Petrochemical manufacturing & 875 & 27.4 & $\begin{array}{l}G T-M H R \\
\text { HTR-PM }\end{array}$ & $\begin{array}{c}\text { IMSR-400 } \\
X e-100\end{array}$ \\
\hline & IP6 & $\begin{array}{l}\text { Nitrogenous fertilizer } \\
\text { manufacturing }\end{array}$ & 850 & 81.4 & $\begin{array}{l}G T-M H R \\
\text { HTR-PM }\end{array}$ & $\begin{array}{c}\text { IMSR-400 } \\
X e-100\end{array}$ \\
\hline & IP7 & Pulp mills & 800 & 71.1 & $\begin{array}{l}G T-M H R \\
\text { HTR-PM } \\
\end{array}$ & $\begin{array}{c}\text { IMSR-400 } \\
X e-100 \\
\end{array}$ \\
\hline & IP8 & $\begin{array}{l}\text { Petroleum refineries (gasoline, } \\
\text { diesel, kerosene) }\end{array}$ & 600 & 95.3 & $\begin{array}{l}X e-100 \\
\text { MSTW }\end{array}$ & $\begin{array}{c}P B M R \\
I S M R-400\end{array}$ \\
\hline \multirow{7}{*}{$\begin{array}{l}\text { Tier } 3 \\
300-50\end{array}$} & IP9 & Potash, soda, and borate mining & 300 & 300.9 & $\begin{array}{c}L F R-A S-200 \\
M S R-F U J I\end{array}$ & $\begin{array}{l}\text { IMSR-400 } \\
\text { PBMR }\end{array}$ \\
\hline & IP10 & $\begin{array}{l}\text { Plastics, material, and resin } \\
\text { manufacturing }\end{array}$ & 291 & 122.7 & $\begin{array}{l}\text { LEADIR-PS100 } \\
\text { MSTW }\end{array}$ & $\begin{array}{c}\text { AFR-100 } \\
\text { Xe-100 }\end{array}$ \\
\hline & IP11 & Ethyl alcohol manufacturing & 266 & 20.4 & $\begin{array}{c}4 S \\
\text { LEADIR-PS100 } \\
\end{array}$ & CLEAR-I \\
\hline & IP12 & $\begin{array}{l}\text { Alkalis, chlorine, and sodium } \\
\text { hydroxide manufacturing }\end{array}$ & 177 & 49.3 & $\begin{array}{l}\text { AFR-100 } \\
X e-100 \\
\text { SEALER } \\
\text { SSTAR } \\
\end{array}$ & $\begin{array}{c}4 S \\
\text { LEADIR- } \\
\text { PS100 } \\
\text { CLEAR-I }\end{array}$ \\
\hline & IP13 & $\begin{array}{l}\text { Starch, corn gluten feed, corn } \\
\text { gluten meal, corn oil } \\
\text { manufacturing }\end{array}$ & 177 & $93.3^{*}$ & $\begin{array}{l}\text { SEALER } \\
\text { SSTAR } \\
4 S \\
\end{array}$ & $\begin{array}{l}\text { LEADIR- } \\
\text { PS100 } \\
\text { CLEAR-I }\end{array}$ \\
\hline & $\begin{array}{l}\text { IP14 } \\
\text { IP15 }\end{array}$ & $\begin{array}{l}\text { Paper mills } \\
\text { Paperboard mills }\end{array}$ & 150 & 244.2 & $\begin{array}{c}L F R-A S-200 \\
M S R-F U J I\end{array}$ & $\begin{array}{c}\text { IMSR-400 } \\
\text { PBMR }\end{array}$ \\
\hline & IP16 & Wet corn milling & 50 & $93.3^{*}$ & $\begin{array}{l}\text { SEALER } \\
\text { SSTAR } \\
4 S\end{array}$ & $\begin{array}{l}\text { LEADIR- } \\
\text { PS100 } \\
\text { CLEAR-I }\end{array}$ \\
\hline
\end{tabular}




\subsection{DYNAMIC SYSTEM MODELS ADVANCED REACTOR INTEGRATED ENERGY SYSTEMS USING TRANSFORM}

Based on the previous discussion on advanced reactors types and applications, balance-of-plant technologies from two reactor concepts were selected to modeled using the dynamic system modeling tool TRANSFORM, which is the underlying Modelica library used for much of the IES program's physics-based system modeling. Selection of the two technologies and the extent of the system to model was based on the following criteria.

1. Ensure a sufficient amount publicly available design information for model generation. This work is intended to be widely accessible to demonstrate and expand modeling capabilities and therefore must not have restricted access. Sufficiency is determined based on whether enough design information is available (e.g., nominal operating conditions and system description) to develop a model without requiring additional design work.

2. Support the off-the-shelf approach proposed as part of many advanced reactor concepts. The power production loop or balance-of-plant (BOP) of the reactors is not typically considered unique. Therefore, the BOP is an excellent choice for modeling, as it is required for most IESs, and it is expected to be essentially interchangeable between primary heat generation systems.

3. Expand the experience base of IES and TRANSFORM applications. To date, there has been minimal modeling performed within the IES program that is associated directly with advanced reactors due to previous (and now obsolete) DOE directives. However, several models of advanced reactors have been created using TRANSFORM. On the other hand, the BOP of advanced reactors has received little attention from IES and TRANSFORM, so it is a fruitful area for modeling since it is important for all IESs. TRANSFORM has mostly been used to simulate secondary loop parameters based on a steam turbine cycle, so non-steam BOP models will likely be most useful for expanding the experience base.

4. Contribute to the TRLs of the IES and individual systems. Mature technologies such as LWR technology and traditional steam Rankine cycles are supported by decades of experience and are fairly entrenched in their development and operation paths. There are also many tools that can be used to explore their operation. Technologies with lower TRLs can readily benefit from highlevel system models, as they provide designers and analysts with the opportunity to explore "what-if" scenarios early in the design lifecycle. This feedback loop can help ensure that future technologies are properly designed from the start, with a robust and efficient technology as the TRL improves. Therefore, the selected technologies should be early enough in their development cycle to benefit from being modeled within the IES program.

Evaluation of these criteria in the context of IESs and the discussion of advanced reactors in this report led to the selection of two key BOPs: A helium Brayton cycle, and a supercritical $\mathrm{CO}_{2}(\mathrm{~S}-\mathrm{CO} 2)$ Brayton cycle. Sufficient public information was identified for a variant of each of these systems to be modeled in the context of advanced reactors. These two systems are proposed for many advanced reactors and IESrelated applications, but they have not been modeled within IES or TRANSFORM, and they are currently at a relatively low TRL. Thus, these two systems have been identified as providing the most value to the IES program at this time in the context of this report.

The remainder of this section discusses each of the technologies modeled, the approach applied to the creation of the dynamic model, and an example of each system's operation at steady-state and under a hypothetical transient scenario, as may be demanded of an IES [9]. 


\subsection{TRANSIENT SCENARIO}

To test the dynamic capability of each BOP model, an electrical power production profile from an actual operating nuclear facility was used. The selected facility was Cattenom Unit 2, which is located in France. An approximately 5.5-day power history was taken from a public repository managed by the French transmission system operator Réseau de Transport d'Électricité (RTE) [17]. The raw data were scaled to the nominal output of Cattenom Unit 2 of $1300 \mathrm{MW}$, so each of the dynamic models use the normalized (0-1) power profile, individually scaled to the size of the developed BOP. Figure 4.4-1 presents the normalized profile that was used as the grid demand driving the simulation behavior.

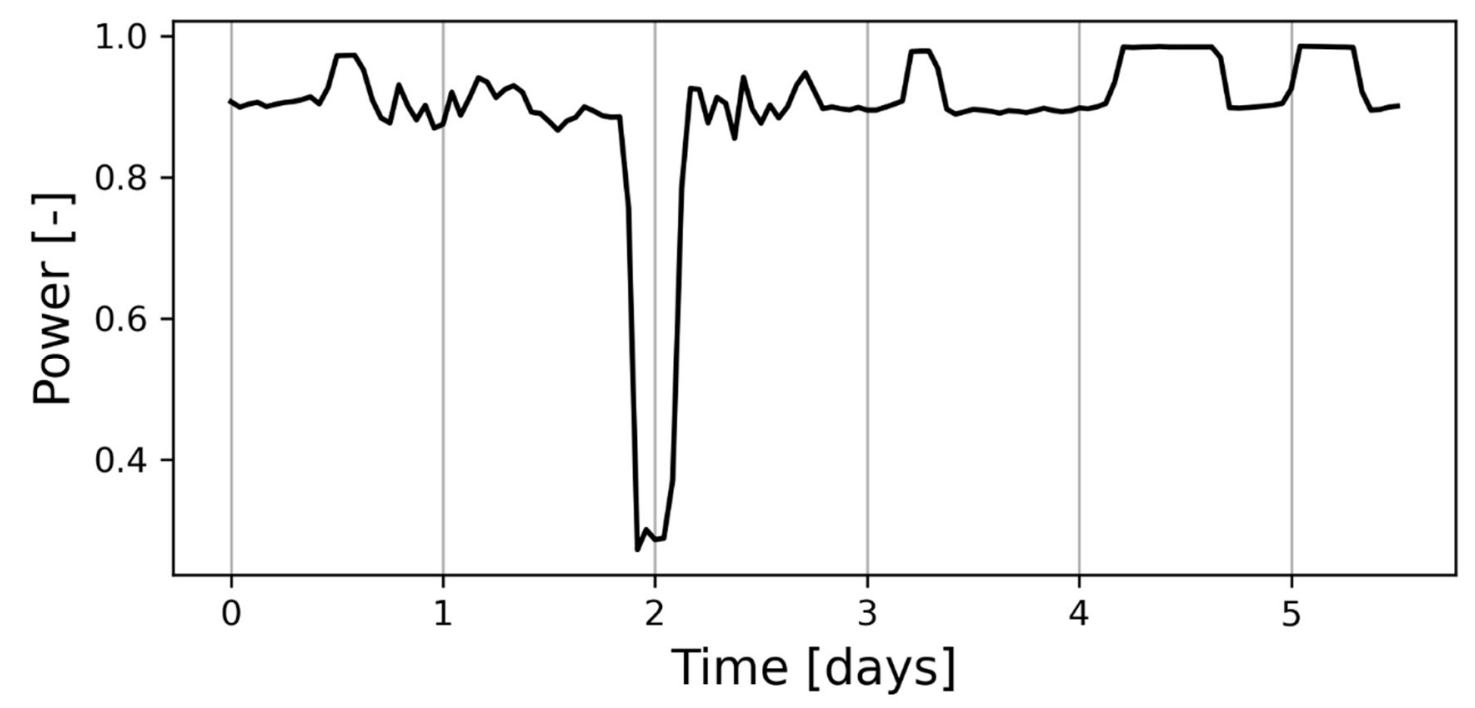

Figure 4.4-1. Normalized power history of Cattenom Unit 2 used as the driving electrical demand of the developed models.

\subsection{1 $\quad \mathrm{S}-\mathrm{CO}_{2}$ Brayton Cycle}

The $\mathrm{S}-\mathrm{CO}_{2}$ power cycle uses carbon dioxide as the working fluid at a temperature and pressure above its critical point at which the fluid will expand in a fashion similar to a gas but maintain a density similar to that of a fluid. Another peculiarity of the $\mathrm{S}-\mathrm{CO}_{2}$ power cycle is that some of its thermophysical behaviors lead to a more compact, less corrosive power cycle which is very efficient compared to traditional Rankine cycles. Although there are many variations of $\mathrm{S}-\mathrm{CO}_{2}$ cycles proposed $[19,20]$, the version presented here is based on the Advanced Fast Reactor (AFR-100) - a sodium fast-spectrum reactor core with a $\mathrm{S}-\mathrm{CO}_{2}$ power production cycle [16].

\subsubsection{AFR-100 S-CO2 Thermodynamic Power Cycle}

The AFR-100 S- $-\mathrm{CO}_{2}$ power cycle absorbs $250 \mathrm{MW}$ of thermal heat from the reactor system to generate approximately $150 \mathrm{MW}$ of electricity. The overall system includes the sodium-to-S- $\mathrm{CO}_{2}$ reactor heat exchanger ( $r h x$ ), a turbine (turbine), a high and low temperature reheater ( $h t r$ and ltr), an $\mathrm{S}-\mathrm{CO}_{2}-$ to-water heat exchanger (cooler), and a low and a high temperature compressor (compressor 1 and compressor 2 ). Figure 4.4-2 presents a process flow diagram (PFD) created in TRANSFORM with the nominal operating setpoints as presented in the AFR-100 report [16]. 


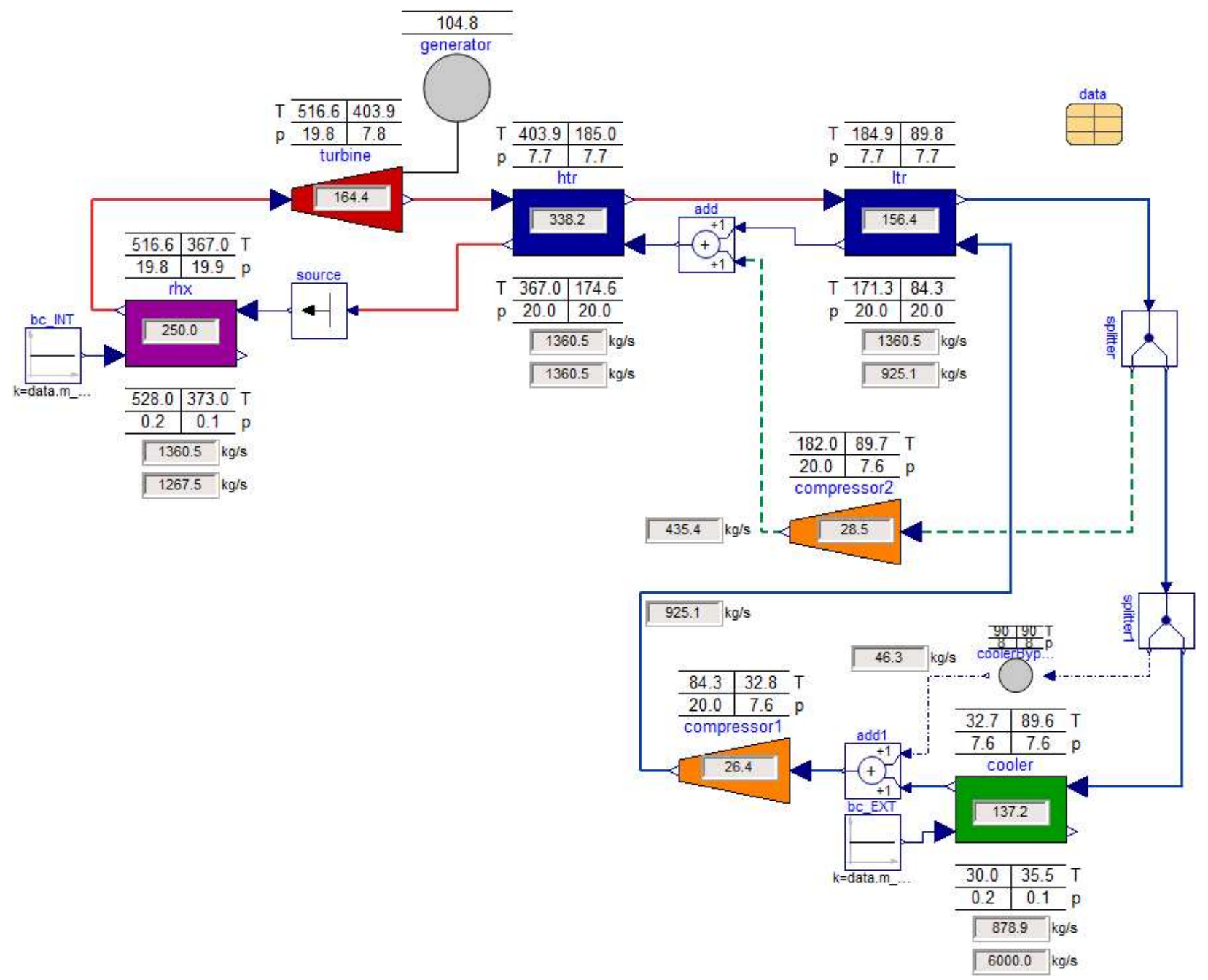

Figure 4.4-2. PFD for the AFR-100 S-CO2 Brayton cycle.

\subsubsection{Assumptions}

The S- $\mathrm{CO}_{2}$ model consisted of state points and nominal operating conditions. Although it has limited ability to model a physically driven model (e.g., no pipe diameters or wall thicknesses), a more traditional system model can be achieved. When a dynamic model of the system was being created, assumptions were made regarding fluid volumes which may cause over- or under-estimation of the system's time constant. Other performance information (e.g., pump curves) is not known, so basic nominal maps were used to emulate the typical behaviors expected from pumps. Finally, because limited information was available on proper control strategies and the inventory make-up system, reasonable approximations and simplified controls were used. This will lead to non-optimized performance of the system during transients, but the variables to create and improve strategies are available and can be refined in future work.

\subsubsection{Methodology}

Although the final dynamic model is of interest and useful, in reality, the approach applied to successfully create the model is of more value, as it required significant effort. Therefore, discussion of the methodology can provide useful recommendations for creating future models and will thereby increase 
the likelihood of success. This section presents not only the final dynamic model, but also the approach applied to create the $\mathrm{S}-\mathrm{CO}_{2}$ model.

\section{$\underline{\text { Step } 1 \text { - Gather Model Information }}$}

The first step in creating the model was to identify the necessary information required to model the system. This included identifying publications which contain information on the system of interest, as well as additional supporting information (e.g., other publications, code manuals, knowledgeable persons) to help flesh out potential gaps in design publication or to provide insight into modeling decisions to help create a more robust model. An example of a useful document for the $\mathrm{S}-\mathrm{CO}_{2}$ model was the report on a system code for S-CO $\mathrm{CO}_{2}$ Brayton cycles from ANL [16] Argonne National Laboratory [20] which helped fill in gaps of potential control strategies and bypass lines that are not included in the AFR-100 design report.

\section{$\underline{\text { Step } 2 \text { - Record Nominal Data }}$}

Publications typically indicate a natural transition in an activity or type of work to capture the status of the work up to that point. However, when models, tables, and written documents are being used, lags in reporting the most current information can result in updates not being included. Inconsistencies between tables, plots, and text often occur during typical workflows as a result of the demands placed on the authors and an ever-evolving reactor design. Therefore, it is important to have a structured way to record and verify that the system description does not contain a detectable and avoidable error.

The approach to recording the original data for the $\mathrm{S}-\mathrm{CO}_{2}$ work was to first create an independent record within TRANSFORM containing all design information. This independent record was called "Data." This record allows a naming strategy to be established, along with an organizational approach to the available information. This ensures that the development of the system model will be more tractable. For each component $(*)$, this work adopted the nomenclature of $m_{-}$flow ${ }^{*}$ for the mass flow rate, state ${ }^{*}{ }_{-} a / b$ for the inlet and outlet $(a / b)$, and $Q_{-}{ }^{*}$ for the heat flow rate. With the record information entered, the resulting model was then included in the models as "data" (Figure 4.4-2) so that all references to nominal conditions could be made to that implementation. This approach ensured that all design data were consistent throughout the model development cycle.

\section{$\underline{\text { Step } 3 \text {-Verify Nominal Data }}$}

For this work, verification of the now-recorded data was a two-step process. The first step began with the creation of a simple PFD (Figure 4.4-2) to ensure all the data was recorded correctly from the design document and that they appeared reasonable along the flow path (e.g., temperatures did not increase when they should have decreased). Simple, customized visual indicators were created for this work to present the PFD in a manner similar to the PFD in the original AFR-100 document, thus enabling additional visual verification. The second process involved creating individual unit tests for each component using the nominal conditions as boundaries (Figure 4.4-3). This process verified that the resulting calculations (e.g., outlet temperatures) were correct, and it also ensured that the underlying thermophysical property database being used was consistent, within expected error, of that used for the design document. At this stage, either steady-state or dynamic components could be used, depending on the application. For the S$\mathrm{CO}_{2}$ model, steady-state components were used (e.g., log-mean temperature difference heat exchangers without heat capacity). 


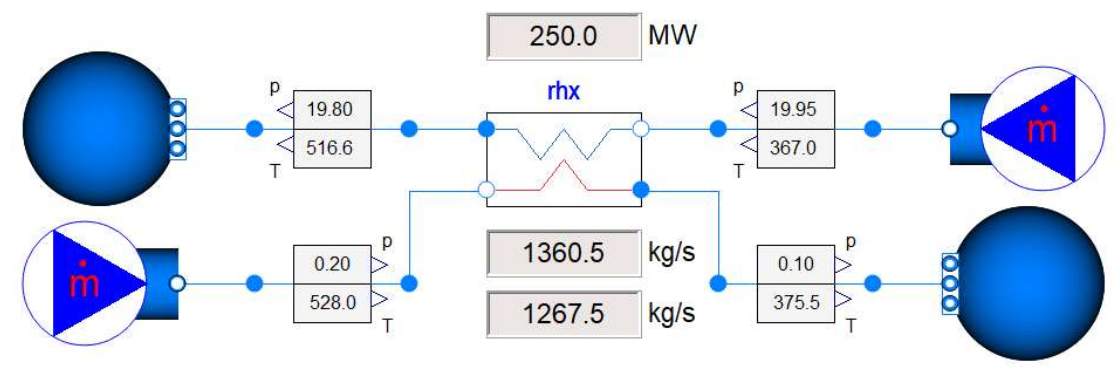

Figure 4.4-3. Example of a unit test of individual components to verify nominal data.

\section{$\underline{\text { Step } 4 \text { - Create a Steady-State Model }}$}

With the input data verified to the extent necessary to ensure that there was neither a gross error in transcribing data nor in the original calculations, it was appropriate to begin assembling the full model. At this stage, a steady-state or dynamic model may be appropriate, depending on the system. The $\mathrm{S}-\mathrm{CO}_{2}$ system modeled consisted of little detail on specific component designs, so the more simplistic individual steady-state-based unit tests were linked together one at a time until the entire model was connected and successfully simulating. Once all unit tests were connected, all state points (e.g., pressure) were finetuned and verified to match the nominal data. Small volumes or resistances are often placed between components to relax potential numerical issues. This is a standard practice for model development and is not unique to this work, so it does not merit further discussion. The resulting steady-state model is shown in Figure 4.4-4. At this stage, small deviations from the nominal conditions may begin to occur due to the complexities of a closed system model which does not artificially enforce boundary conditions. A mature steady-state model may also serve provide a robust initialization scheme for the dynamic model. However, though achievable, this level of maturity in steady-state modeling within TRANSFORM is current not implemented.

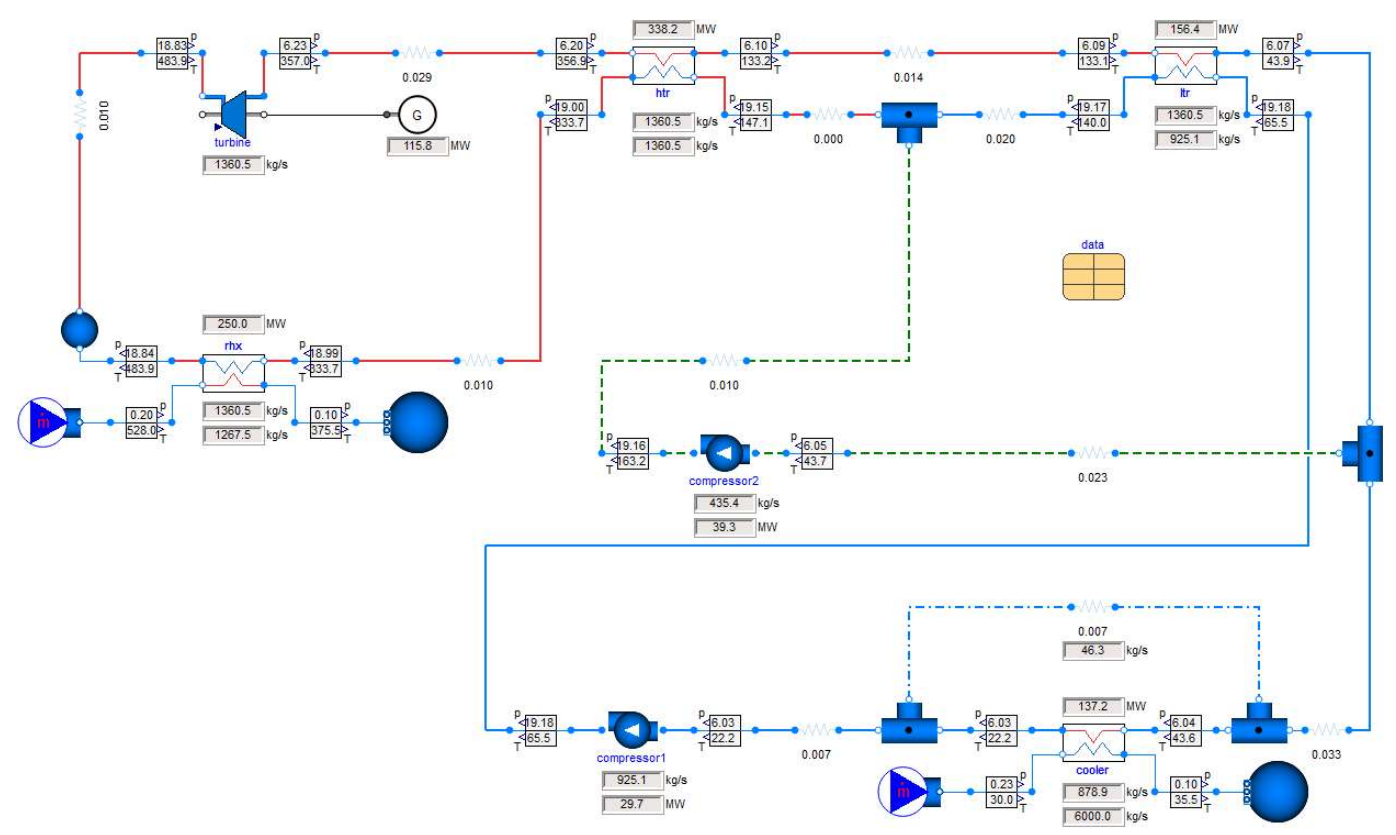

Figure 4.4-4. A steady-state model of the $\mathrm{S}-\mathrm{CO}_{2} \mathrm{BOP}$ for the AFR-100. 


\section{$\underline{\text { Step } 5 \text { - Create a Dynamic Model }}$}

If a full steady-state model is created, then the next step is to replace the principal components that are not appropriate for a dynamic model. The principal components in the $\mathrm{S}-\mathrm{CO}_{2}$ model were the log-mean temperature difference heat exchangers, each of which was replaced with a simple distributed heat exchanger that enables the user to specify the fluid volumes and the number of volumes while retaining the overall heat transfer coefficient calculated from the steady-state model to drive heat transfer. Once the heat exchangers were replaced, additional volumes were introduced into the model (e.g., tee components), and a pressure boundary representing the inventory control system was added. The pressure boundary is commonly included to help achieve the desired system pressure while suppressing large pressure swings during transient maneuvers. During this step, it may also be helpful to include small transients such as pump impeller speed in the model to ensure that the system is robust and capable of future simulations.

\section{Step 6 - Create Control Systems}

With a completed dynamic model control systems can now be explored to successfully cover the scenarios of interest. As previously described, the transient scenario used in this work scope was load following an electrical grid power demand profile. To achieve load-following behavior for the S- $\mathrm{CO}_{2}$ model, a turbine bypass valve was introduced to allow fluid to be diverted around the turbine (i.e., a turbine bypass valve). The opening of the valve was set by the response of a proportional-integral (PI) controller in an attempt to match the measured power from the generator to the setpoint power. An additional PI controller with a response approximately 20 times slower was also placed on the rhx mass flow rate so that under larger power transients, the required power could still be delivered. A possible physical analog to that operation is exemplified by increases or decreases in reactor power which correspond to changes in primary mass flow rate to keep the system temperature at its nominal operating state. Although they are not used in this simulation, many other potential variables are available to the modeler to manipulate the behavior of the control system. For example, variables for the pressure boundary (tank), pump control methods, or the cooler bypass can be manipulated based on specific control strategies.

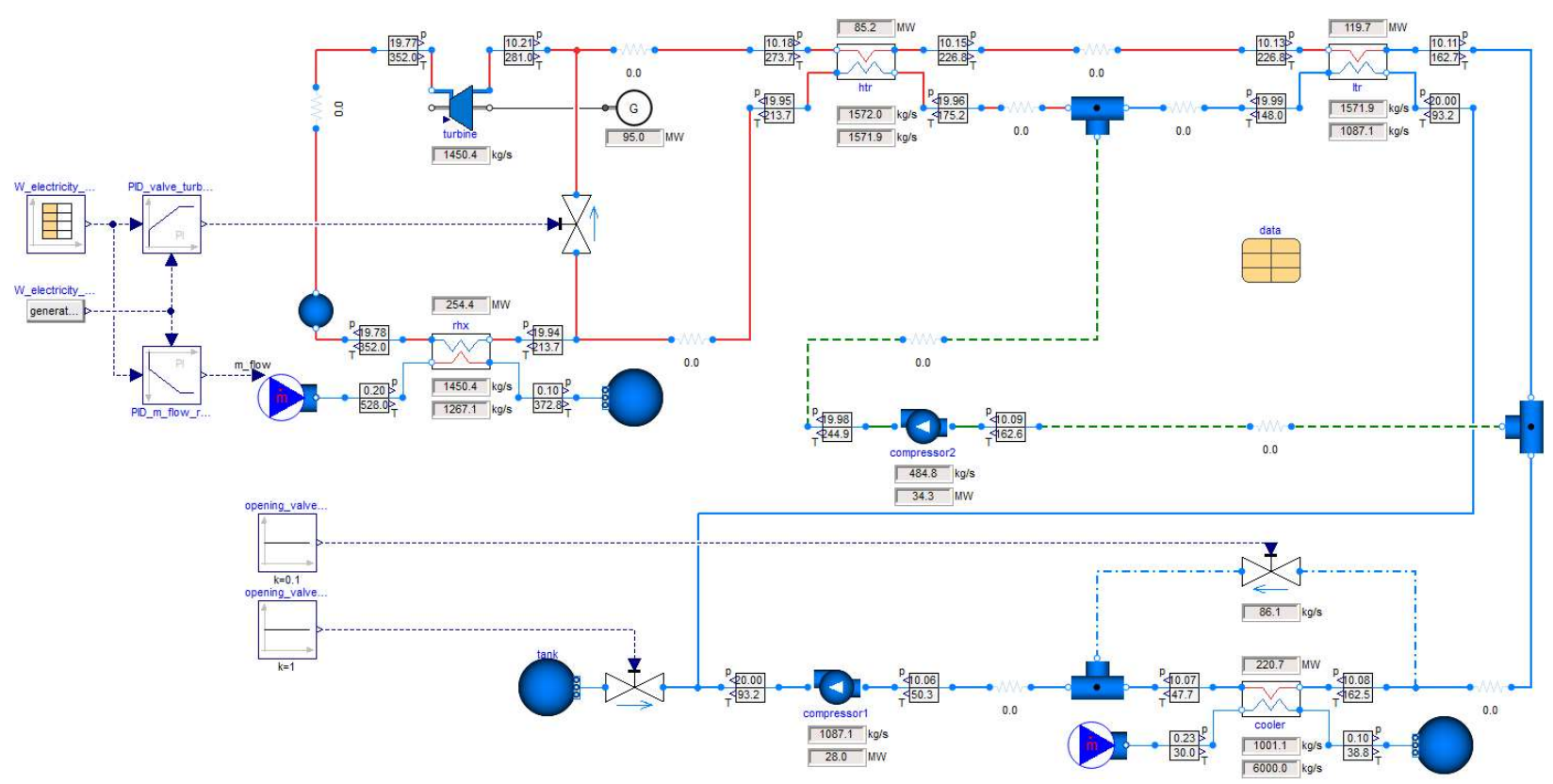

Figure 4.4-5. Dynamic model of the $\mathrm{S}-\mathrm{CO}_{2} \mathrm{BOP}$ for the AFR-100 with some basic controls implemented. 
$\underline{\text { Step } 7 \text { - Setup Result Evaluation Workflow }}$

At this stage in the model lifecycle, naming conventions and principal components are generally mature, and most if not all modeling issues have been identified and corrected. Therefore, it is useful to move results visualization from the simulation environment, which does provide some basic plotting capabilities, to a more robust platform for results exploration. The Python programming language and the vast set of open-source libraries are recommended. It is within this additional software/language where final plots for presentation and publication are made to ensure the consistency and quality of plots. This process also provides a robust way to readily recreate plots as new simulation results are made available.

\section{$\underline{\text { Step } 8 \text { - Iterate on Scenarios, Model, and Controls as Needed }}$}

Now that design information has been collected and verified, models have been generated with initial control systems, and pipelines for data exploration and publication have been generated, additional scenarios and incremental improvements or expansions of the base model can be performed. At this point, the modeler can have confidence in the capability of the model to perform a variety of operations and to rapidly visualize results. These capabilities facilitate discussion and allow for iterations on scenarios, models, controls, and/or visualization techniques as needed.

\subsubsection{Results}

The $\mathrm{S}-\mathrm{CO}_{2}$ dynamic model with the specified simplistic control schemes was simulated using the driving power history described above. The simulation overview is shown in Table 4.4-1. The overall power generated as compared to the setpoint is shown in Figure 4.4-6. Note that the ability of the system to follow the transient is highly dependent on the control systems implemented. The largest difference occurs at the rapid transient toward the end of day 1. More robust controls or additional systems could reduce the difference.

Table 4.4-1. S- $\mathrm{CO}_{2}$ simulation overview

\begin{tabular}{lc}
\hline Parameter & Value \\
\hline Simulation length (days) & 5.5 \\
Number of simulation points & 7,920 \\
Number of equations & 8,303 \\
CPU time (seconds) & 657 \\
Solver & Esdirk45a \\
\hline
\end{tabular}

Figure 4.4-7 shows the resulting flow distributions which occur throughout the system due to control operations. Note the significant change in turbine flow rates that is required to meet the power demand. This large swing occurred because the controls for the turbine bypass responded much faster than the response of the $r h x$ flow rate. Alternative strategies could force the reactor to drive the majority of the power swing, significantly change the system's behavior.

As with the flow rate, the behavior of the state points throughout the system will be completely controlled by the control system implemented. The current control system allows the temperature and mass flow rate to fluctuate while attempting to only meet power and limit pressure swings. Figure 4.4-8 presents the state points at the beginning of the dynamic simulation, and Figure 4.4-9 presents these same state points at the middle of the transient. 

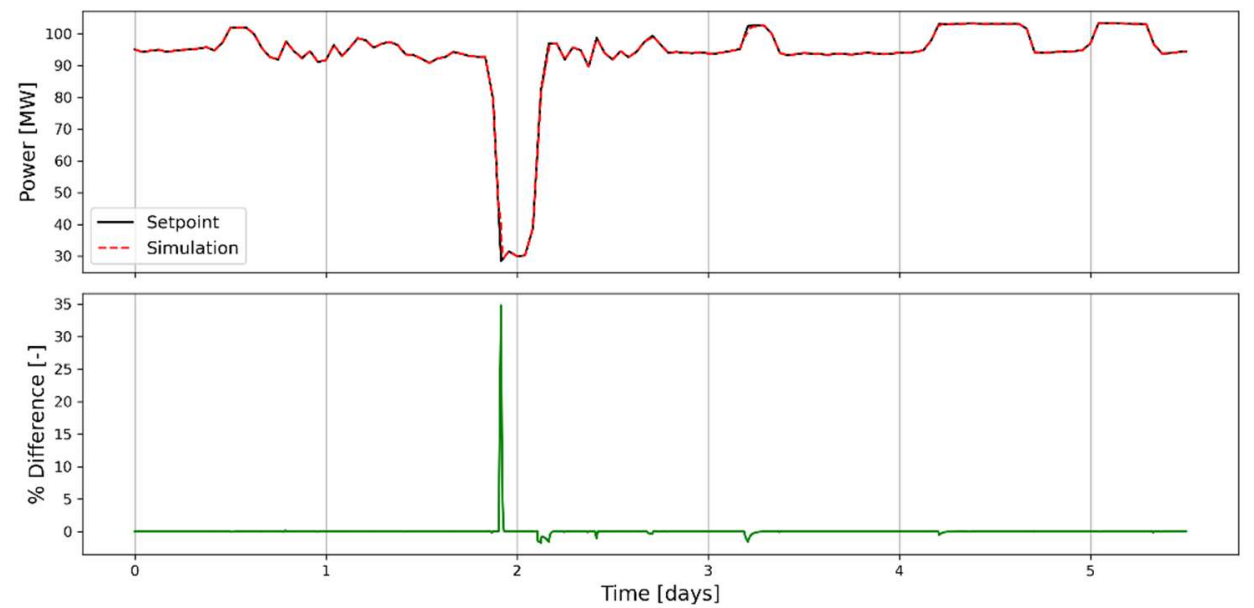

Figure 4.4-6. $\mathrm{S}-\mathrm{CO}_{2}$ model comparison of generated to setpoint power.

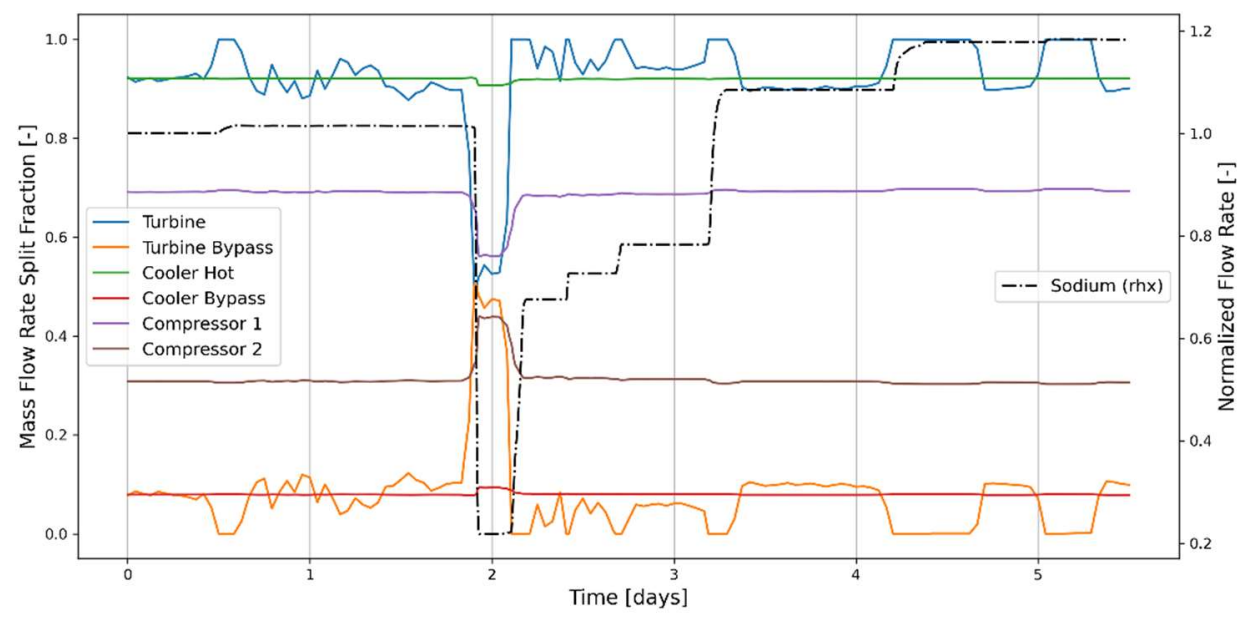

Figure 4.4-7. $\mathrm{S}-\mathrm{CO}_{2}$ model split fractions demonstrating the change in flows to match requested power. 

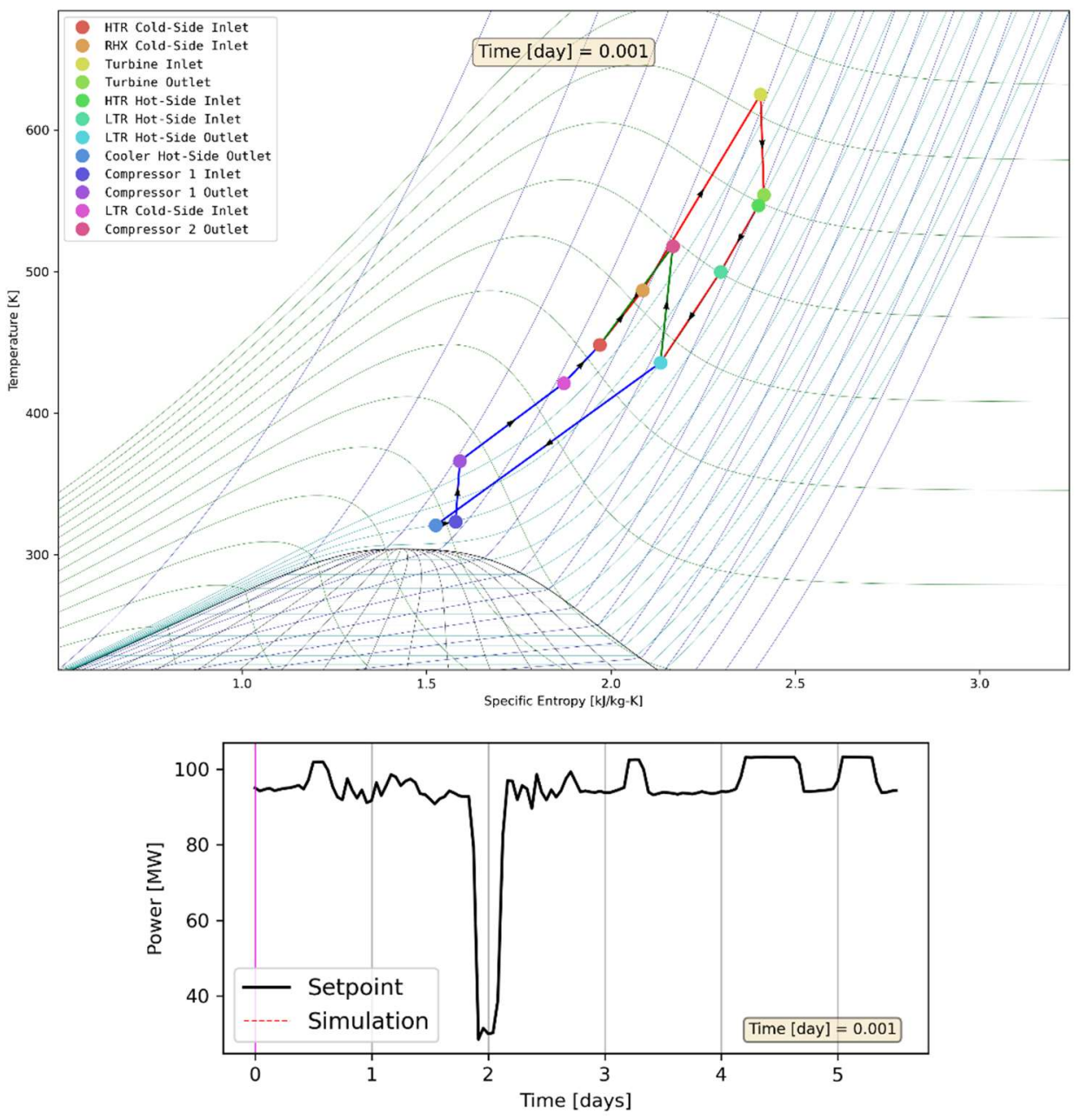

Figure 4.4-8. State points of the $\mathrm{S}-\mathrm{CO}_{2}$ of the dynamic model's simulation at the beginning.

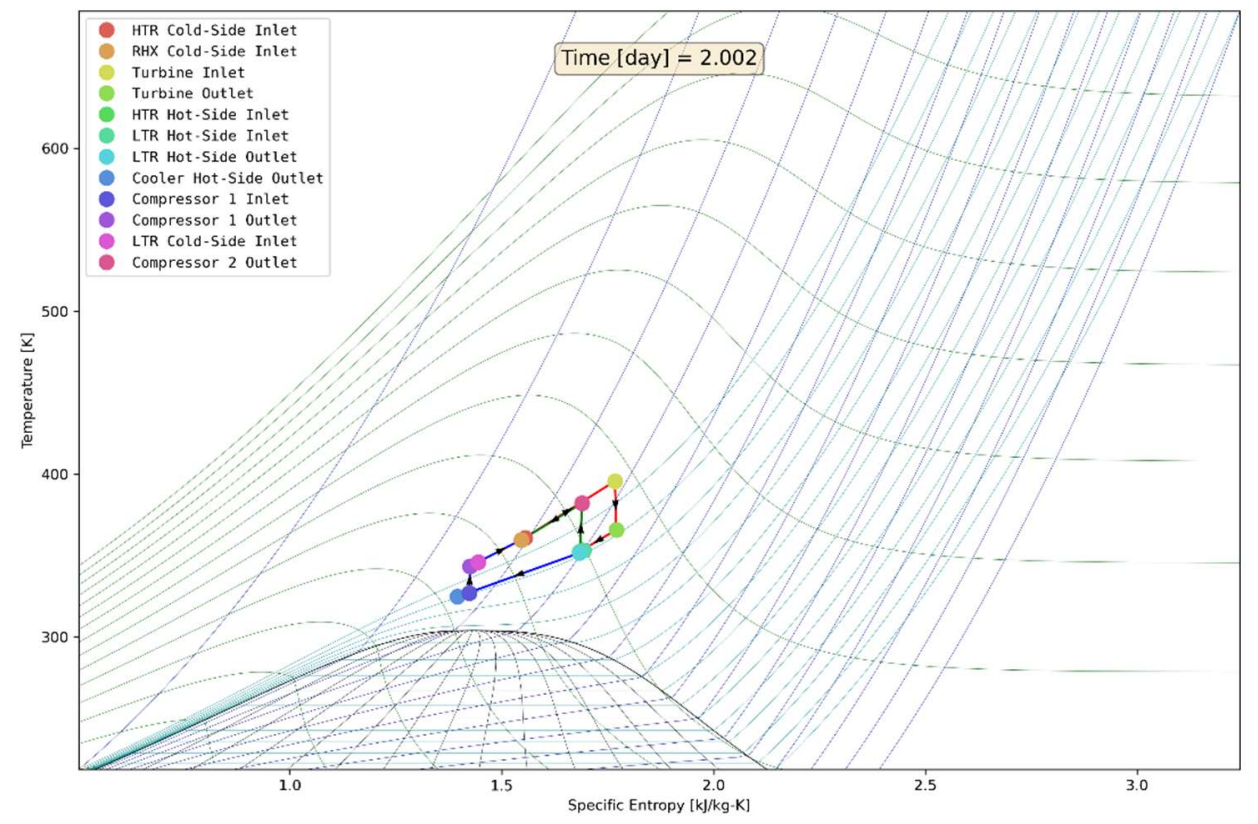




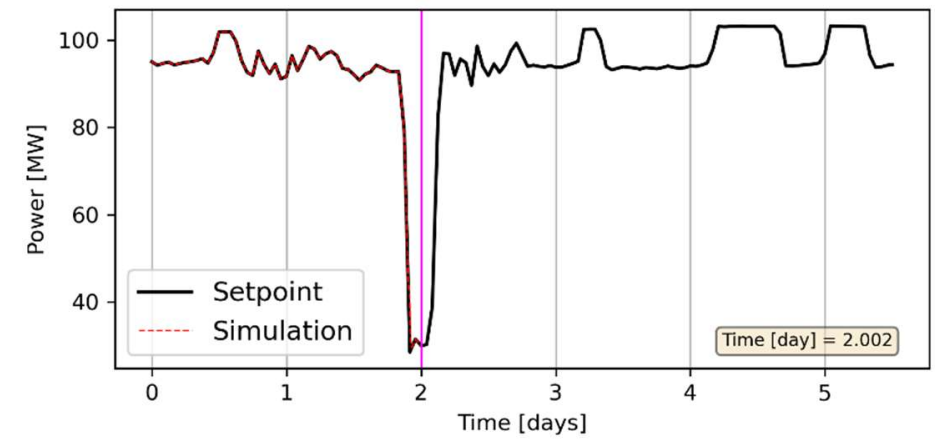

Figure 4.4-9. State points of the $\mathrm{S}-\mathrm{CO}_{2}$ of the dynamic model's simulation during the middle of the extreme transient.

\subsubsection{Summary}

A model of a S-CO $-\mathrm{CO}_{2}$ power cycle based on the nominal operating conditions of the AFR-100 was successfully created in TRANSFORM. This model allows for a variety of dynamic simulations controlled by the user-designed control system. A demonstration of the model's ability to load follow using a simple control system is presented herein. The creation of this model builds confidence in the ability for future IES work to incorporate advanced power cycles involving not only reactor systems, but energy storage, as well. More robust general control strategies are recommended for development to enable this and other system-level models to be rapidly adapted to meet alternative operating regimes and to meet realistic operating requirements that cannot be accomplished using simplistic control strategies.

\subsubsection{Helium Brayton Cycle}

The pebble bed modular reactor (PBMR) preliminary design by Pebble Bed Modular Reactor SOC, Ltd., presents a helium Brayton cycle that contains enough public domain information to build a basic model. The basic PBMR approach is similar to other GCR designs that utilize TRISO fuel pebbles and a helium coolant medium. Therefore, a model of this plant's power production cycle would be representative of many pebble bed gas-cooled reactors, so designs applied to the PBMR plant $[12,13,14,15]$ and other GCR designs can be combined to simulate a general GCR design.

The PBMR has been under development by Pebble Bed Modular Reactor SOC, Ltd., since 1996. General diagrams and states are given in Section 4.4.2.3, and they comprise the basic assumptions for the model's fluid states.

\subsubsection{Pebble Bed Reactor Brayton Thermodynamic Power Cycle}

A pebble bed reactor consists of between 200,000 to 500,000 pebble fuel elements, depending on the size of the reactor and pebble properties. Three designs presented in Section 3.1 include a closed Brayton cycle, GTHTR300C, GT-MHR, and PBMR. Because the goal of this simulation is to simulate a power production cycle-focusing mainly on simulating a load follow capability of the thermodynamic cycle within TRANSFORM - the reactor core will consist of a basic heat transfer model and will not contain the basic point kinetics models necessary to truly mimic reactor's response to a load follow transient.

The gas-cooled reactor literature shows that the pebble bed plants typically range from 400 to $600 \mathrm{MWt}, 7$ to $12 \mathrm{MPa}$, and core exit temperatures in excess of $750^{\circ} \mathrm{C}$. It should be noted that as development continues on the various advanced reactor designs, the state point data have been updated in the public domain for all of these designs. Based on this, it is difficult to obtain an exact steady-state representation 
of the reactor core in published papers, so assumptions must be made regarding the exact efficiencies and designs of components to best match the information available.

\subsubsection{Assumptions}

The general schematic of the systems involved in a pebble bed gas-cooled reactor follow the same general design. The reactor core contains the fuel elements which heat helium from $\sim 500$ to $\leq 850^{\circ} \mathrm{C}$. The reactor core for this simulation will have a nominal thermal power of $400 \mathrm{MWt}$. The helium is then passed through a series of turbines that are used to generate power or to power the system's compressors. After passing through the turbines, the gas will pass through a regenerative heat exchanger or recuperator. Finally, the gas will pass through several heat exchangers (precooler and intercooler) in conjunction with the compressors to remove heat, improve cycle efficiency, and pump the coolant. This typical design scheme is followed for many pebble bed gas-cooled reactors (reactor, turbine, regen heat exchanger, precooler, and staged compressors, with an intercooler in between). Because the detailed design parameters are not available in published papers (such as the exact exchanger design, turbine design, piping diameters, compressor dynamics, and control systems), the reactor components are simplistic in their design and are based on the general heat rejection rates and temperatures that are available in the steady-state theoretical data[13, 14]. The assumptions and general design concepts used to create this model remain the same as those presented in Section 4.4.1.2. Once the basic steady-state model is completed and a dynamic model has been put in place to simulate a load follow operation, the simplistic models can be changed using TRANSFORM system's ability to replace the various components with a more detailed model quickly as more information becomes available.

\subsubsection{Methodology Application to Pebble Bed Gas-Cooled Reactor}

The pebble bed gas-cooled reactor design was created following the methodology presented in Section 4.4.1.3 for the AFR-100 S- $\mathrm{CO}_{2}$ design and illustrates how this design method can be used to create different dynamic modeling simulations.

Step 1 - Gather Model Information

State point and plant layout information for the PBMR design [13] was used as a baseline for the creation of the steady-state model. This information gives an idealized version of a theoretical Brayton cycle designed to give a $900^{\circ} \mathrm{C}$ core exit temperature based on a $400 \mathrm{MWt}$ core output at $100 \%$ power and a helium flow rate of 185-195 kg/s. Heat exchangers modeling the pre-cooler and intercooler are based on the heat exchanger concept for the GTHTR300C [18]. With these high-level assumptions in place, the model was separated into each of the GCR components as discussed in Step 1 of the S-CO2 Brayton cycle simulation. Components were adjusted and calibrated until the idealized results were obtained in Step 3. 


\section{$\underline{\text { Step } 2 \text { - Record Nominal Data }}$}

The nominal data used for the pebble bed reactor simulation was taken from Koster [13] and is summarized in Table 4.4-2.

Table 4.4-2. Nominal temperature and pressure conditions for a $400 \mathrm{MWt}$ pebble bed gas-cooled reactor

\begin{tabular}{cccl}
\hline State point & $\begin{array}{c}\mathbf{T} \\
{\left[{ }^{\circ} \mathbf{C}\right]}\end{array}$ & $\begin{array}{c}\text { Pressure } \\
{[\mathbf{M p a}]}\end{array}$ & \multicolumn{1}{c}{ Point descriptions } \\
\hline 1 & 33 & 2.6 & Precooler outlet \\
2 & 130 & 4.7 & Turbo compressor 1 outlet \\
3 & 33 & 4.7 & Intercooler inlet \\
4 & 100 & 7 & Turbo compressor 2 outlet \\
5 & 500 & 7 & Core inlet \\
6 & 900 & 7 & Core outlet \\
7 & 520 & 2.6 & Power turbine outlet \\
8 & 150 & 2.6 & Precooler inlet \\
\hline
\end{tabular}

With this nominal set of data established, a generalized model can be created for each of the conditions stated. 


\section{$\underline{\text { Step } 3 \text {-Verify Nominal Data }}$}

The TRANSFORM model was divided into 5 separate models prior to being linked together. The grouped models are as follows:

1. Reactor: State point 5 to 6

2. Turbine: State point 6 to 7

3. Regen heat exchanger: State point 7 to 8

4. Precooler: State point 8 to 1

5. Compressors: State point $1-4$

For each model, the individual state points were set up as boundary conditions, whereas the components were set up in between, and the specific designs were fine-tuned to provide similar if not identical results.

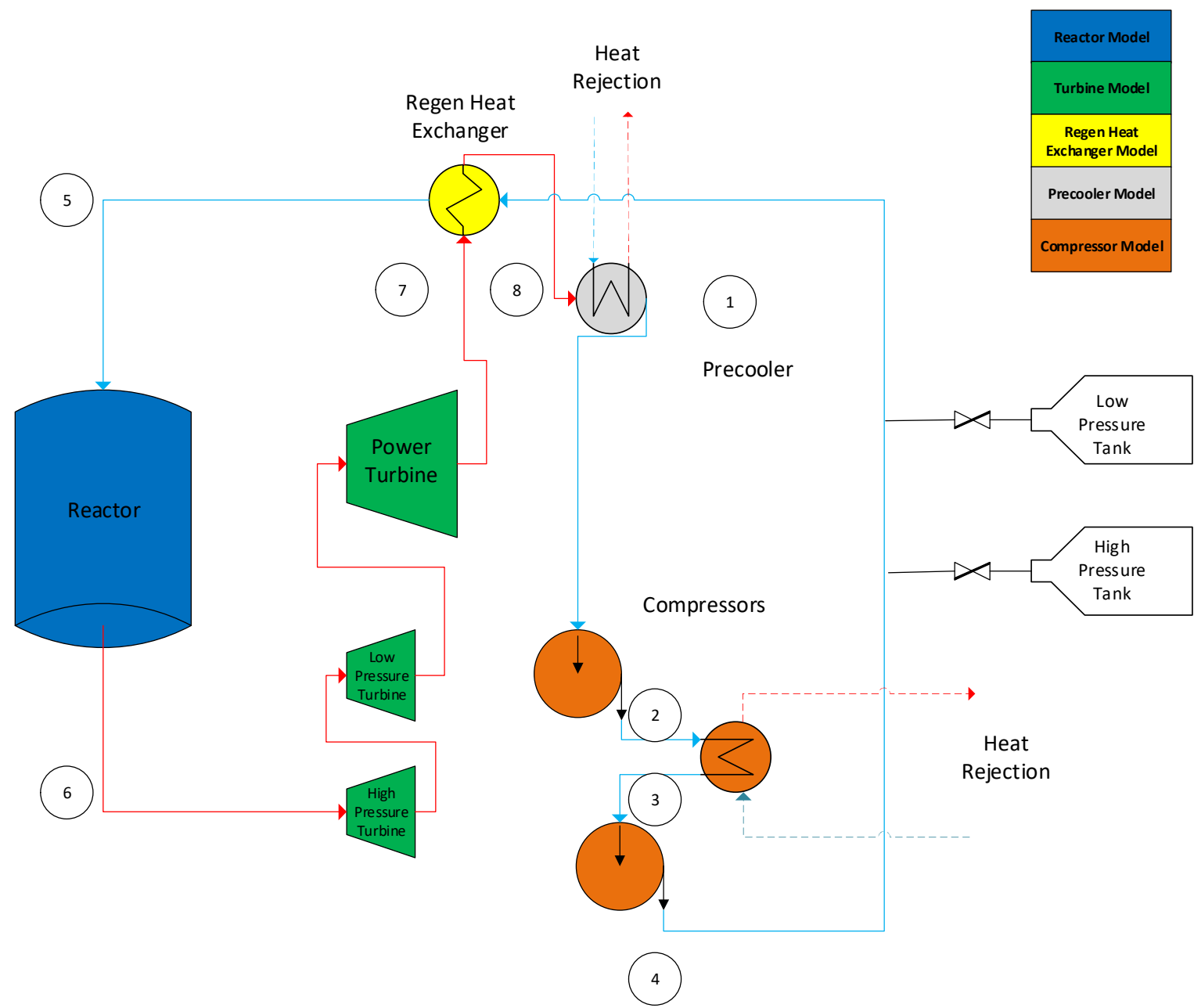

Figure 4.4-10. Basic pebble bed reactor schematic based on the PBMR design [13].

The precooler model is illustrated in Figure 4.4-11, with the boundary conditions set to the appropriate state points. Each component is modeled in a similar fashion until the steady-state data are obtained. 


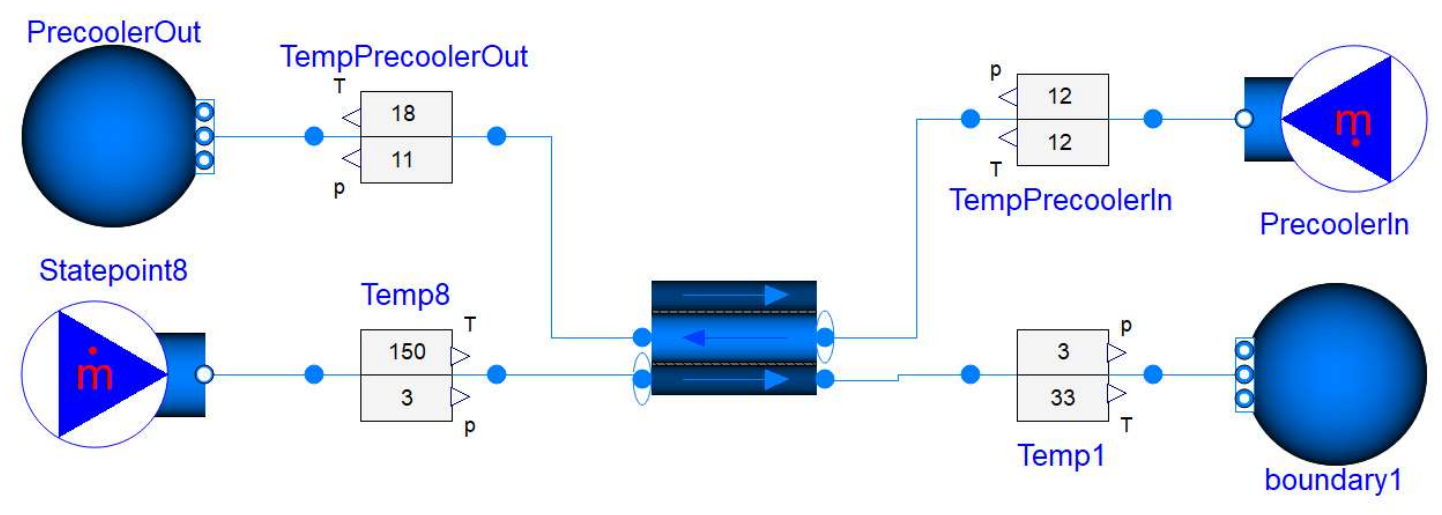

Figure 4.4-11. Basic Stead State Precooler Model steady-state precooler model.

Once each component is benchmarked against available literature data, the model can be assembled, as described in the next step.

\section{$\underline{\text { Step } 4 \text { - Create a Steady-State Model }}$}

Each component was assembled into a single model, and each component was linked to the next in place of the boundary conditions. After each step, the model was run and adjusted to ensure that a reasonable solution was obtained. Small adjustments were made with each link between the various components until a full, closed loop solution was finalized, as shown in Figure 4.4-12. Volumes were added to the model to allow the flow solution to be solved more efficiently. Generally, the literature does not include piping diagrams with the necessary diameters, lengths, and finishes that would allow for development of an accurate pipe model. Those types of deficiencies are accounted for by including volumes and resistances throughout the model. These items can be adjusted to obtain a solution that is more accurate to the steady state. An accurate piping model and design information of the various components would improve the accuracy of the model, but such detailed models are not available at this time. 


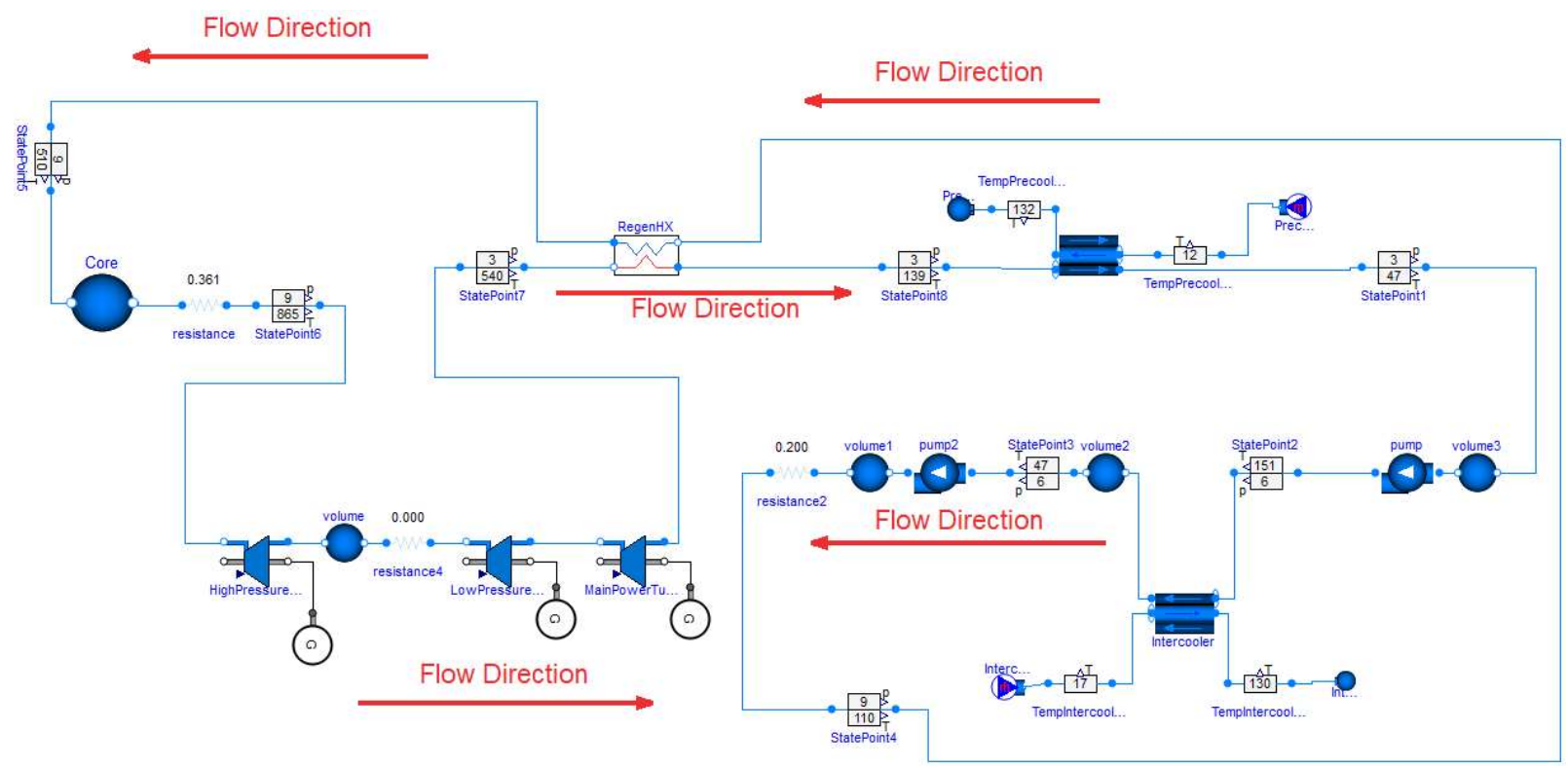

Figure 4.4-12. Steady-state pebble bed reactor model.

Various control systems are not included in the model due to the lack of detailed information on the control logic, design, and usage in the open literature. Additionally, if the core model kinetics were available, they could also be included in the model to provide a more realistic simulation of the plant.

\section{$\underline{\text { Step } 5 \text { - Create a Dynamic Model }}$}

With the steady-state model in place, the-same power demand was entered using as the dynamic state point and was simulated for the same amount of time using a proportional integral derivative (PID) controller for the power input changes. The reactor decay models and point kinetics are being ignored for now and may be included as a future improvement to the model.

\section{$\underline{\text { Step } 6 \text { - Create Control Systems }}$}

The high- and low-pressure inventory control tanks, the compressor, and turbine bypass valve systems are also being ignored. Even though these bypass and inventory controls systems have been built into a steady-state model, the lack of information on how the control systems operate during a transient, as well as the lack of information on their design parameters, prevents them from being modeled in significant detail to mimic real plant operation. Therefore, they are ignored for this simulation. Control for this system is based on the reactor core power.

\section{$\underline{\text { Step } 7 \text { - Setup Result Evaluation Workflow }}$}

Python scripting from Section 4.4.1.4 was used to visualize and properly organize the results. These items are shown in the Results section below.

\section{$\underline{\text { Step } 8 \text { - Iterate on Scenarios, Model, and Controls as Needed }}$}

Very few adjustments were made to this model beyond the steady-state model to obtain a realistic simulation. Iteration and further research are needed to build in a more realistic control system. This would require additional iterations due to the added complexity of the simulation. 


\subsubsection{Results}

The dynamic simulation of a pebble bed gas-cooled reactor with a helium Brayton power cycle was simulated. The simulation overview is shown in Table 4.4-3. The Esdirk45a order 5 stiff algorithm was used as the solver due to the simulation being inherently stiff.

\section{Table 4.4-3. Helium Brayton cycle simulation overview}

\begin{tabular}{lc}
\hline Parameter & Value \\
\hline Simulation length (days) & 5.5 \\
Number of simulation points & 140 \\
Number of equations & 8,030 \\
CPU time (seconds) & 74.4 \\
Solver & Esdirk $45 \mathrm{a}$ \\
\hline
\end{tabular}

Figure 4.4-13 presents the power generation comparison between the Cattenom Unit 2 maneuvers and the simulation. The results show that the simulation set point was run correctly through the entire 5.5-day simulation, with very little error.
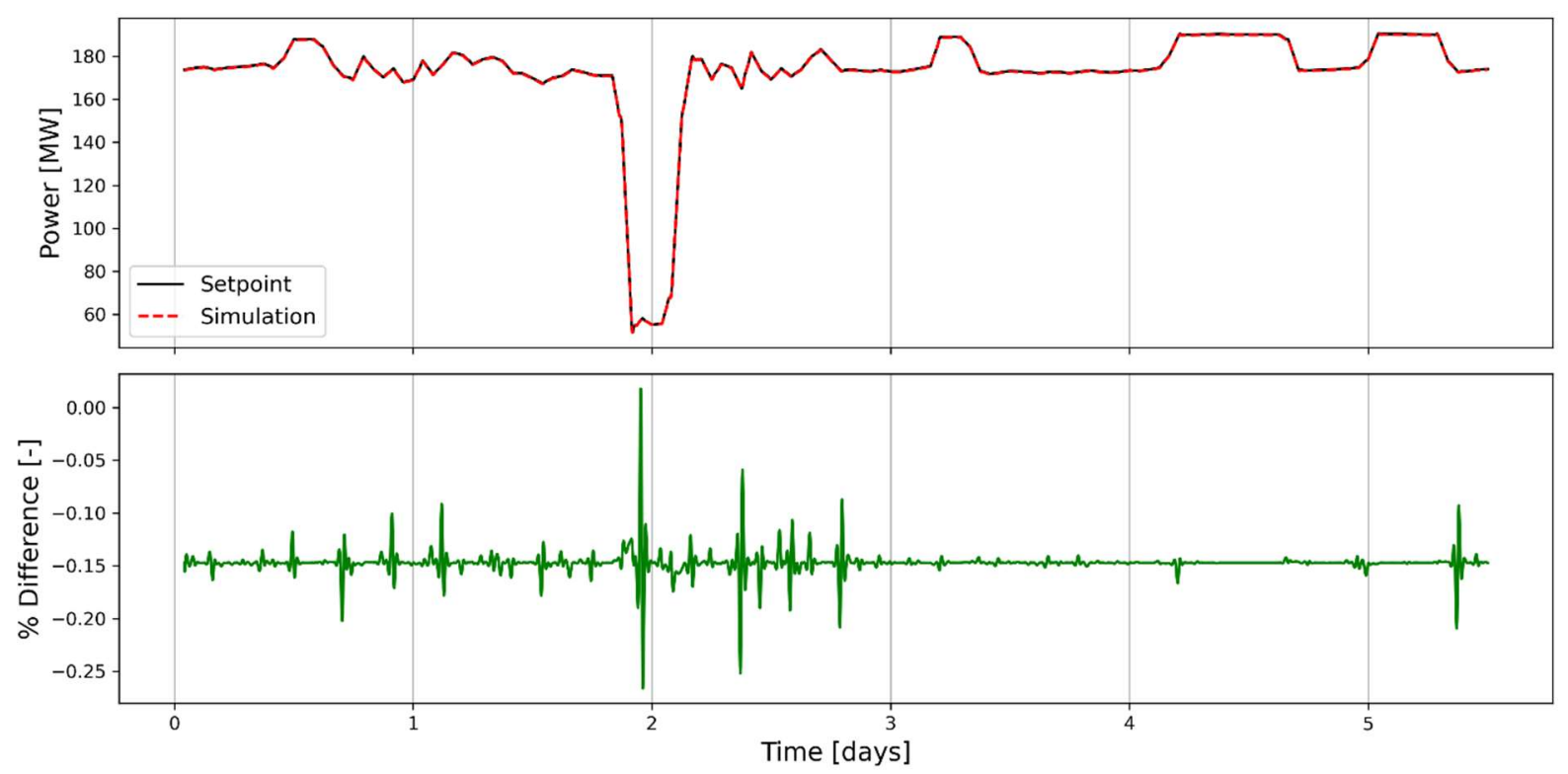

Figure 4.4-13. Power generation comparison between simulation and the Cattenom Unit 2 set point. 
Figure 4.4-14 through Figure 4.4-15 show the specific entropy vs. the temperature diagrams for the system at two illustrative points. Because the control systems for the compressors, bypass controls, and the inventory control system were not modeled, the specific enthalpy diagram for the lower power levels are likely not accurate for the plant's low-level power state. In the future, a more generic control scheme could be implemented to improve the results.
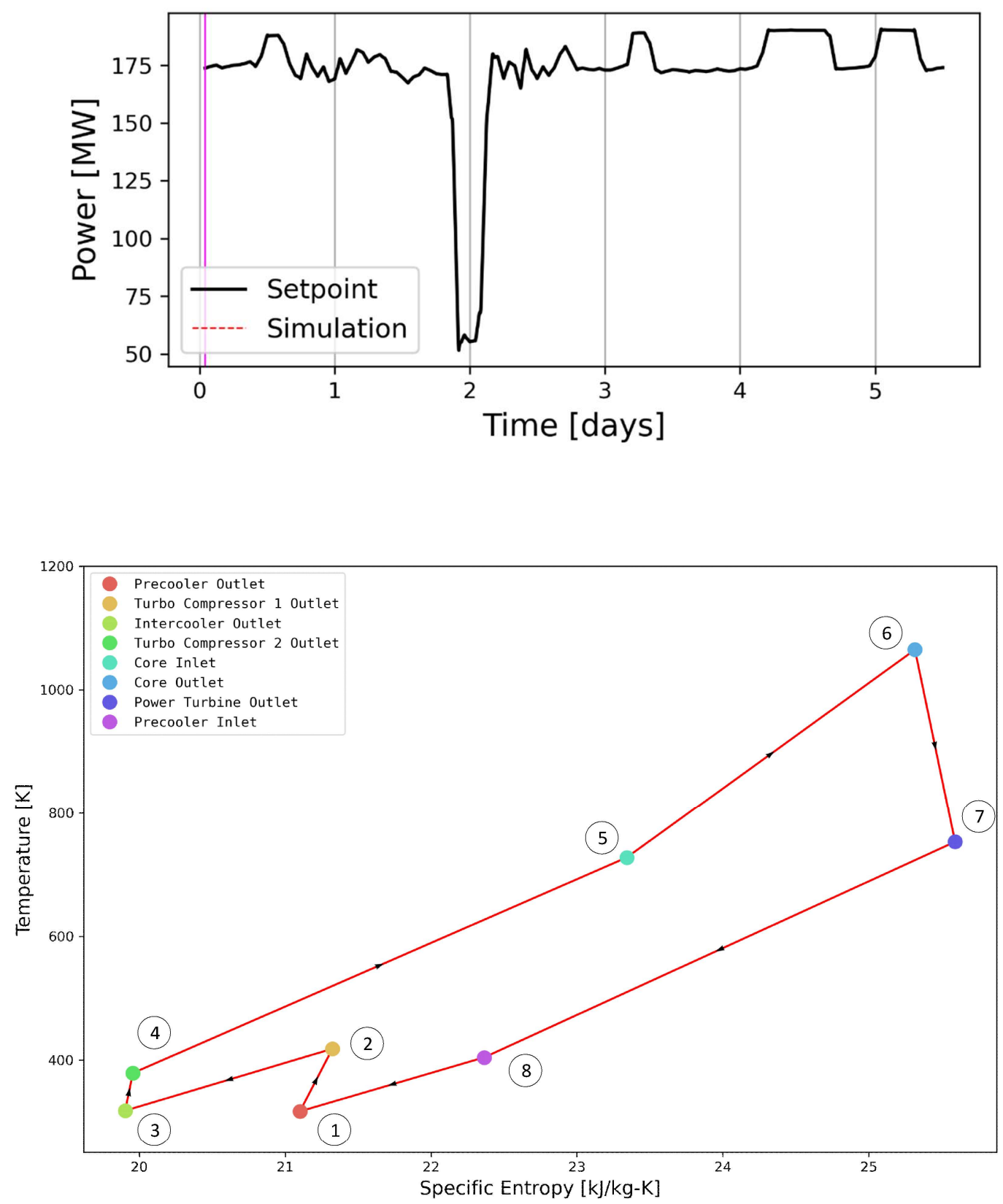

Figure 4.4-14. Temperature vs. specific entropy for transient start. 

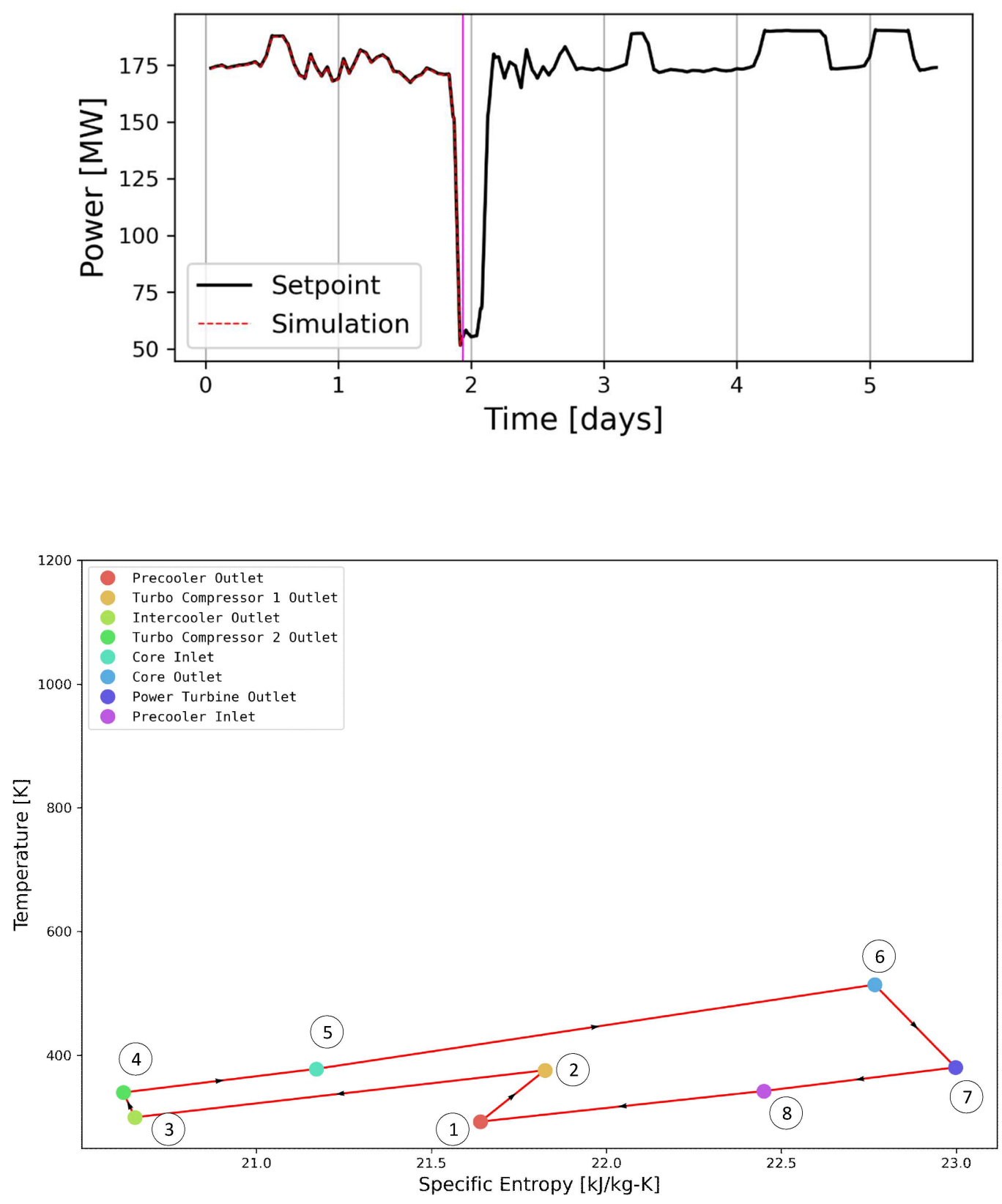

Figure 4.4-15. Temperature vs. specific entropy diagram at the lowest power timestep. 


\subsubsection{Summary}

The results from the steady-state and dynamic simulations are in agreement with the expected results, showing that TRANSFORM has the capabilities to simulate a closed loop helium Brayton cycle for gascooled reactors and using the design methodology presented in Section 4.4.1.3. With this base model in place, the following items can be added using the inherent drag and drop nature of TRANSFORM to modify the current model:

1. Control system and helium inventory system to allow for better simulation of transients.

2. Reactor kinetics model to allow for a more accurate simulation of the reactor core

3. Piping and system losses: results would give a better pressure drop and flow model.

4. Energy storage system: to be used for simulations with a sensible heat storage

5. Industrial process transfer system: to allow for modeling of heat transfer to an industrial process

6. Conduction models: to allow for simulation of component heat up during transients.

All items listed above are within TRANSFORM's current capabilities, but they are limited by (1) the incomplete nature of the data available in published papers, (2) the evolution of the systems over time that may not fully document each change in updated publications, and (3) other problems with lack of detailed designs for components in publicly available documents. 


\section{REFERENCES}

1. S. M. Bragg-Sitton et al., "Integrated Energy Systems: 2020 Roadmap,” INL/EXT-20-57708 Rev. 0, Idaho National Laboratory (2020).

2. International Atomic Energy Agency, "Advanced Reactors Information System (ARIS)," https://www.iaea.org/resources/databases/advanced-reactors-information-system-aris, August 2012.

3. S. Brinton, "Advanced Nuclear Industry," https://www.thirdway.org/report/the-advanced-nuclearindustry, June 15, 2015.

4. Nuclear Energy Agency Generation IV International Forum, “Annual Report 2019," https://www.gen-4.org/.

5. C. Forsberg, "Light Water Reactor Heat Storage for Peak Power and Increased Revenue: Focused Workshop on Near-Term Options," June 2017.

6. C. McMillan, R. Boardman, M. McKellar, et al., "Generation and Use of Thermal Energy in the US Industrial Sector and Opportunities to Reduce its Carbon Emissions," Joint Institute for Strategic Energy Analysis, NREL/TP-6A50-66763, INL/EXT-16-39680, December 2016.

7. T. Kim, T. Taiwo, N. Stauff, G. Alberti, et. al., "Compendium Report on the Performance Analysis of Innovative Nuclear Energy Systems,” NTRD-FCO-2018-00438, August 30, 2018.

8. H.D. Gougar (INL), R. A. Bari (BNL), et al. "Assessment of the Technical Maturity of Generation IV Concepts for Test or Demonstration Reactor Applications," INL/EXT-15-36427, Revision 2, October 2015.

9. C. Cany, C. Mansilla, G. Mathonnière, P. da Costa, "Nuclear Power Supply: Going against the Misconceptions. Evidence of Nuclear Flexibility from the French Experience," Energy, 151, pp. 289296, 2018.

10. US Census Bureau. n.d. "North American Industry Classification System (NAICS)." http://www.census.gov/eos/www/naics/, February 2021.

11. US Environmental Protection Agency, Greenhouse Gas Reporting Program (GHGRP), epa.gov, https:/www.epa.gov/sites/production/files/2020-11/2019 data_summary_spreadsheets.zip, February 2021.

12. Status report 70 - Pebble Bed Modular Reactor (PBMR), https://aris.iaea.org/PDF/PBMR.pdf, IAEA ARIS Database.

13. A. Koster, H.D. Matzner, and D.R. Nichols, "PBMR Design for the Future," Nuclear Engineering and Design, 222, pp. 231-245, 2003.

14. P. J. Venter, M. N. Mitchell, and F. Fortier, "PBMR Reactor Design and Development," $18^{\text {th }}$ International Conference on Structural Mechanics in Reactor Technology (SMiRT 18), Beijing, China, August 7-12, 2005, SMiRT18- S02-2.

15. D. Matzer, "PBMR Project Status and the Way Ahead," $2^{\text {nd }}$ International Topical Meeting on High Temperature Reactor Technology, Beijing, China, September 22-24,2004, \#Paper A04.

16. C. Grandy, J. Sienicki, A. Moisseytsev, L. Krajtl, M. Farmer, and T.K. Kim, “Advanced Fast Reactor - 100 (AFR-100) Report for the Technical Review Panel," https://publications.anl.gov/anlpubs/2014/08/79118.pdf, June 2014.

17. Réseau de Transport d'Électricité, “Cattenom 2 Power History,” 2021 (February 4 - October 2, 2021), https://www.services-rte.com/en/view-data-published-by-rte/generation-achieved-by-unit.html. 
18. N. Hirota, A. Terada, X. L. Yan, et al., “A Concept of Intermediate Heat Exchanger for HighTemperature Gas Reactor Hydrogen and Power Cogeneration System," ICONE26-81718, Proceedings of the $26^{\text {th }}$ International Conference on Nuclear Engineering, July 2018, London, England.

19. Y. Ahn, S.J. Bae, M. Kim, S.K. Cho, S. Baik, J.I Lee, J.E. Cha, "Review of supercritical CO2 power cycle technology and current status of research and development. Nuclear Engineering and Technology," 47, pp. 647-661 (2015). https://doi.org/10.1016/j.net.2015.06.009

20. Conboy, T., Wright, S.: Experimental Investigation of the S-CO2 Condensing Cycle. 14 (2011)

21. A. Moisseytsev, J.J. Sienicki, "PDC: Plant Dynamics Code for Design and Transient Analysis of Supercritical Brayton Cycles. Argonne National Lab," ANL-ART-154 (ANL), Argonne, IL (United States) (2018) 10.2172/1483844 